\title{
A Corpus-Based Study of Complex Prepositions in a Non-Native English Variety
}

\author{
Roseline Abonego Adejare \\ Department of Language, Arts and Social Science Education, Lagos State University, Lagos, Nigeria \\ Email:abonego@yahoo.com
}

How to cite this paper: Adejare, R. A. (2020). A Corpus-Based Study of Complex Prepositions in a Non-Native English Variety. Open Journal of Modern Linguistics, 10, 215-259.

https://doi.org/10.4236/ojml.2020.104014

Received: June 9, 2020

Accepted: July 17, 2020

Published: July 20, 2020

Copyright (C) 2020 by author(s) and Scientific Research Publishing Inc. This work is licensed under the Creative Commons Attribution International License (CC BY 4.0).

http://creativecommons.org/licenses/by/4.0/ (c) (i) Open Access

\begin{abstract}
This corpus-based study examined the occurrence and distribution of complex prepositions of the preposition-noun-preposition (PNP)-construction in a non-native English variety with a view to characterising it in the grammar. The data comprised 63 PNP-constructions with 585 occurrences retrieved from the 1,010,382-word International Corpus of English-Nigeria (2015). Motivated by the dearth of works on non-native varieties and underpinned by Construction Grammar, the study revealed an occurrence rate of 579 per million words (pmw). The PNP-constructions were one-and-a-half times more frequent in written $(755 \mathrm{pmw})$ than in spoken (464 pmw) English and were most frequent in the domain Governance \& Law (1368 pmw) and least frequent in General Interest Texts (402 pmw). Administrative Writing was the text type with the highest frequency of PNP-construction occurrence (2151 pmw), followed by Parliamentary Debates (1686 pmw); Demonstrations figured the least (49 pmw). In terms of, in addition to, in spite of and on behalf of were the prominent forms, respectively occurring 144, 37.6, 35.6 and 30.7 times pmw. Respect was the highest manifesting semantic category (49 percent) and its respect/disregard strain was dominant in Unscripted Speeches and Administrative Writing; time posted the lowest (0.2 percent). Whereas all the 63 PNP-constructions featured in the British National Corpus (BNC), only 6.1 percent of BNC's132 low frequency forms also occurred in ICE-Nigeria. While 17 percent of BNC's 30 most frequent PNP-constructions did not manifest in ICE-Nigeria, 64 percent of those present occurred more frequently in BNC than in ICE-Nigeria, with the differential as wide as 33:2.
\end{abstract}

\section{Keywords}

Complex Prepositions, PNP-Constructions, Non-Native English, Nigerian English, ICE-Nigeria 


\section{Introduction}

\subsection{Background}

The preposition is one of the eight word classes acknowledged in the grammar. It heads the prepositional phrase (PP) (e.g. in the car), which functions as post modifier in the noun phrase (e.g. The children in the car were waiting for their mother), adjunct in the clause structure (e.g. The children were in the car), and verb complement (e.g. Nobody was watching over the children in the car). It expresses a relationship (of space, time, or other abstract relations) between two or more entities in the clause, usually between its nominal complement and another item. A preposition can be simple or complex. It is simple if it consists of only one word (e.g. at and before); otherwise it is complex (Strang, 1969: p. 19; Quirk et al., 1985: pp. 657-673; Greenbaum, 1996: p. 161; Carter \& McCarthy, 2006: p. 468).

A complex preposition (CP) consists of two or more words (e.g. because of, in addition to and in the case off). Attempts at delineating CPs by defining them and setting criteria for their identification point to one inherent attribute: syntactic wholeness. One such attempt is Quirk et al.'s (1985: pp. 671-672), who recognise as CP "a sequence that is indivisible both in terms of syntax and in terms of meaning". Their nine criteria testing the syntactic wholeness of CPswhich include invariability of the second prepositional element and the noun with respect to number and determiners-prove that whereas the sequence in spite of is a CP on the shelf by is not. Halliday and Matthiessen (2004: p. 359) note that CPs such as in front of evolved from PPs, with nouns such as front as complement. They add that those sequences which become prepositions typically occur without deictic preceding the noun and that the noun occurs in the singular only. This means that sequences such as in the case of and on the ground of are still in the process of becoming prepositions. Complex prepositions are thus like idioms which, though of multiple words, are considered one and stored as such in the mental lexicon. In this study focus is on the three-word CP devoid of pre-modification; it is a study of the preposition-noun-preposition sequence, otherwise known as the PNP-construction.

Quirk et al. (1985: p. 670) classify CPs of the PNP-construction into four syntactic categories based on the type of preposition before and after the noun, with a miscellaneous fifth group. These are in + noun + of (e.g. in aid of), in + noun + with (e.g. in accordance with), by + noun + of (e.g. by virtue of), on + noun + of (e.g. on account of), and others (e.g. in addition to, in return for and with/in regard to). They also identify with examples a number of meanings associated with the PNP-constructions thus: Relative position (vertical: on top of, horizontal: in front of), Concession (in spite off), Respect (with reference to; in respect off), Addition (in addition to), Cause, reason, motive (on account of), Viewpoint (with respect to), and Antithetic conjunct (in comparison with, by way of, in contrast to).

While it is not absolutely correct to state that there is a paucity of studies on prepositions and CPs, given the current state of development in theory and de- 
scription, it must be acknowledged that gaps exist in respect of PNP-constructions. To begin with, Tyler and Evans' (2003) elaborate description of the prepositional meanings does not cover CPs. Where they get some attention, the focus is on select two-word sequences, to the neglect of PNP-constructions. A few examples will suffice. Hirao's (2016) grammaticalization study focuses on the two-word sequence down below. Inoue (2019) concentrates on the functions of until byl before as CPs while Cappele's (2001) demonstration of out of as a real preposition does not extend to PNP-constructions. Although Hoffmann (2011) uses data from Kenyan English for the comparative aspect of his analysis, the topic investigated is the distribution of preposition pied-piping and stranding in different clause types and not CPs.

\subsection{Statement of the Problem}

Existing corpus-based studies of prepositions and CPs are limited to native English and are largely diachronic and synchronic. While the general orientation is either strictly grammatical (e.g. Hoffmann, 2005) or fixatedly semantic (Tyler \& Evans, 2003), none is both grammatical and semantic in emphasis, or qualitative and quantitative in analytical approach. The pattern of behaviour of CPs in text types-such as Editorials and Broadcast Discussion-has not been accounted for in depth and attention has been limited to select PNP-constructions in the corpora. Moreover, outside the five works published before its final compilation and release in 2015 (none of which is on CPs), this researcher is unaware of any studies based on the relatively new International Corpus of English-Nigeria (2015). In essence, there is no study of CPs of the PNP-construction that is based on the non-native English corpus, ICE-Nigeria. Yet, such studies are important in view of the place of prepositions in the grammar of English and the contributions non-native varieties make towards the growth and development of English as a world language. A study of this nature stands to greatly enhance the general understanding of the grammar of Nigerian English as a significant variety of World English.

\subsection{Purpose of the Study}

This study examines the occurrence and distribution of CPs of the PNP-construction in a non-native variety of English with a view to characterising it in the grammar. It intends to answer the following research questions:

1) Do complex prepositions of the PNP-construction occur in non-native English such as Nigerian English? If so, how frequently do they figure and which syntactic patterns are the most productive?

2) What are the patterns of distribution of the PNP-constructions in spoken and written varieties of Nigerian English as represented by ICE-Nigeria?

3) How do the PNP-constructions occur in different text types and what explanations are there for variations in frequency of occurrence?

4) Which prepositional meanings are most frequent and which forms indicate 
them? How does the frequency distribution of meanings vary with respect to text types and form?

5) Are there similarities and differences between native and non-native varieties of English with respect to the pattern of occurrence of complex prepositions of the PNP-construction?

6) Are there deviations from the norm in terms of PNP-construction usage?

\subsection{Previous Studies}

One justification Hoffmann (2005) gave for investigating grammaticalization and the use of English CPs was that the subject had received "little scholarly attention". Sadly, the situation has not significantly improved, which further justifies the current research endeavour. Consequently, there are not that many pertinent studies available for review. Nevertheless, this section is concerned with a review of previous studies of CPs of the PNP-construction.

McGranahan's (1971) work on scientific Russian is one of the earliest corpus-based studies of CPs. It contains English equivalents and the corpus comprises 350,000 words. One of its findings is that CPs in Russian start with the equivalent of the English in and that the equivalent of in the case of is the form with the most number of occurrences (193) while that of in terms of is among the least (6). The absence of a well-articulated quantitative analysis limits the insights gain-able into the behaviour of CPs in that domain as well as the possibility of comparison with similar corpora. Salihbašić (2018) analyses the most commonly used English CPs in EU documentation and their Croatian equivalents, with focus on their syntactic and semantic similarities and differences. The corpus size is 202,818 (107,589 for English), the domains covered are six (Commission Decision, Agreement, Decision, Commission Notice, Regulation, and Directive) and the semantic types are eight. The study however fails to state the frequency of the forms studied even within the domains covered.

Klègr (1997) undertakes a semantic approach to the study of CPs of the PNPconstruction aimed at drawing attention to "an enormous amount of word combinations with prepositional functions... and the need to outline their formal, functional and semantic properties". The data comprises 444 forms with their 473 appearances. Klègr classifies the $\mathrm{CPs}$ into twenty-five minor (e.g. possession) and eight major (e.g. process) semantic categories, assigns each preposition accordingly and determines the frequency of the different semantic categories. Process is the most recurring major semantic category (23.8 percent), followed by delimitation and contingency with 21.4 percent each. Degree is the least (1.1 percent). He accounts for the "surfeit of contingency strings" in terms of "the intellectualization of language" and explains the increase in circumstantial prepositions in terms of desire for greater explicitness of the relations expressed. Klègr's semantic classification is adopted for this study because of its comprehensiveness.

Hoffmann's (2005) book-length study predicated upon the grammaticalization theory provides a detailed description of the historical development and 
present-day uses of English CPs of the PNP-construction. So, it is both diachronic and synchronic, with the synchronic data based on the approximately 100 million-word BNC. Adopting the quantitative approach, Hoffmann compares the general distribution of some of the 30 most frequent CPs of the PNP-construction in Present-Day English in different domains and accounts for low frequency ones as well. He demonstrates that although the PNP-constructions comprise three orthographically distinct words, they are conceptualised as a single syntactic unit based on the underlying assumption that

[Language] use can be interpreted as a reflection of the cognitive processes at work during the production of language. Thus, if complex prepositions do indeed have the status of units of grammar, they will be stored and retrieved from memory as whole entities rather than being assembled on the basis of the compositional rules of syntax (p. 2).

Among others, Hoffmann reveals that in terms of is the most frequent PNPconstruction and that high domain-specific use is typical of a whole range of $\mathrm{CPs}$, such as the 139 occurrences per million words of in relation to in the Social Sciences and the high and low frequency of in spite of in World Affairs and Applied Sciences respectively. Aspects of Hoffmann's results form the data-base for the envisaged comparison between native and non-native English in terms of the occurrence and distribution of CPs of the PNP-construction.

\section{Theoretical Framework}

This study of CPs of the PNP-construction is predicated upon Construction Grammar, a family of theories within the field of cognitive and evolutionary linguistics which posits that human language consists of constructions or learned pairings of linguistic forms with functions (meanings). Constructions are stored pairings of form and meaning-covering everything, from the morpheme to the sentence-and are so defined if one or more of its properties are not strictly predictable from its component parts or from other existing constructions in the grammar (Goldberg, 1995: p. 5; Goldberg, 2003: p. 220). The PNP-sequences under investigation are constructions because their forms and meanings have been demonstrated to be unpredictable from their component parts or from other constructions (See Hoffmann, 2005).

Hoffmann and Trousdale (2013) trace the origin of construction to Ferdinand de Saussure whose notion of arbitrary and conventional pairing of form and meaning became to be extended to all levels of grammatical description beyond words or morphemes. They add that it is this extended notion of the Saussurean sign that has become known as a "construction" and that the use of the term construction as form-meaning pairings actually dates back to the twelfth-century Medieval Linguists. Construction Grammar therefore refers to the different linguistic approaches that explore the notion of form-meaning pairings. Goldberg (1995: p. 6) and Croft and Cruise (2004: p. 266) however credit Charles Fillmore, Paul Kay and others with the development of the theory through their works pub- 
lished in mid 1980. As Kay and Fillmore (1999: p. 1) make explicit, adopting a constructional approach entails making an undertaking to commitment in principle to account for the entirety of each language. This means that every pattern has equal right as data for which grammar must provide an account. No piece of data is deemed irrelevant to grammatical theory as Construction Grammar takes seemingly inconsequential items into consideration. The increasing importance attached to natural language data and the availability of computational and statistical techniques for data retrieval and analysis provided impetus for the theory's growth and development.

Although generative because it accounts for allowable and non-allowable expressions in the grammar alike, Construction Grammar is not transformational. It considers traditional constructions of the form-meaning-correspondences the basic units of language and shares an interest in characterising the entire class of structures that make up language - not just the structures that are considered "core grammar"-because there are theoretical benefits accruable to even "core" areas from studying the so-called "non-core" or periphery cases. In other words, it accounts for all of our knowledge of language as patterns of form and function (Goldberg, 1995, 2003).

Justification for adopting Construction Grammar for this study is three-fold. First, the PNP-sequences focused upon here are themselves constructions; they are exponents of the word class preposition, which itself belongs to the syntactic unit WORD. Since constructions are basic units of language (Goldberg \& Suttle, 2010: p. 5), Construction Grammar is considered adequate for handling data of this nature. Second, Construction Grammarians assume that abstract patterns such as the preposition-noun-preposition sequence are stored form-meaning pairings, in the same way as ordinary everyday words like goat and yam, which makes it applicable to non-native English data that ICE-Nigeria represents. For example, it would be possible to account for deviations in PNP-construction usage in terms of what Hoffmann (2011) describes as limited input frequency determining the quality of output in L2 English. Finally, Construction Grammar is chosen rather than, say, Grammaticalization Theory-which postulates a direct connection between context of use and the gradual development of language (Hoffmann, 2005: p. 2)-because this study is purely synchronic and is not concerned with establishing the grammatical status of CPs. Construction Grammar therefore has the capacity to handle this study's data at its different stages.

\section{Methodology}

\subsection{The Corpus}

The ICE-Nigeria compiled between 2007 and 2014 by an eighteen-member Project Team headed by Professor Ulrike Gut is the corpus. Downloaded on 5 November 2019 using the link http://sourceforge.net/projects/ice-nigeria, ICE-Nigeria contains $1,010,382$ words made up of 400,796 words of written and 609,586 words of spoken components. The written component comprises 17 text types 
with 510 files while the spoken component has 15 text types with 392 files. There are 32 text types with 902 files altogether, as Table 1(a) and Table 1(b) display.

\subsection{The Data}

To retrieve the data I read through every file, identified and copied out each form in its sentence context, marked the forms for recognisability, and noted the exact line of occurrence for identification ease. Thereafter, I listed all the PNPconstructions in all the files (e.g. 01-26) contained in a text type (e.g. bdis) in sequential order of occurrence. Using the tally system I indicated the number of times each form occurred in a given file and ignored files that do not feature any form. The total number of PNP-constructions in a text type and their frequency of occurrence were determined this way. This was done separately for the written and spoken components. To determine the number and variety of the PNP-constructions in both components, I drew two separate tables and listed all the forms with their frequency in each text type. These were later added together. There were 48 PNP-constructions with combined frequency of 303 in the written component (See Table 2) and 46 forms with 282 occurrences in the spoken component (See Table 3). Because the same forms generally occurred in both the spoken and written components and because some forms also featured only in the one and not in the other component, it became expedient to synthesise both components in order to obtain the overall data. There were 63 PNPconstructions with 585 occurrences altogether (See Table 4). This constitutes the data.

\subsection{The Manual Retrieval Option}

Manual retrieval of the PNP-constructions was the option because none of the Regular Expression Engines such as Practical Extraction and Report Language (Perl) was within reach. Moreover, applying the Windows (CRLF) search engine (which is only available for the written component) created serious problems. Since the syntactic variety and number of PNP-constructions in a given file (if any) could not be ascertained before hand, typing in a sequence at a time (e.g. on behalf of) as a search strategy was both frustratingly slow and unhelpful: It left out low frequency forms apart from the fact that even inputted high frequency ones did not always manifest. Though laborious and time consuming, manual retrieval exposed me to the contents of most of the 902 files. The relatively small size of ICE-Nigeria, which is slightly over a million words, made it contemplate-able in the first place.

\subsection{Data Analysis}

Both the quantitative and qualitative approaches to data analysis were employed in this study. It proceeded as follows. First, having determined the number and frequency of forms in the 32 text types, the spoken and written components and the entire corpus, I proceeded to calculate the proportion of the corpus that each 
Table 1. (a) ICE-Nigeria written component; (b) ICE-Nigeria spoken component.

(a)

\begin{tabular}{cccc}
\hline S/N & Text Type & File Name \& Number & Words \\
\hline 1 & Academic writing humanities (W2A) & AHum_01-11 & 20,014 \\
2 & Academic writing natural sciences (W2A) & ANsc_01-11 & 20,017 \\
3 & Academic writing social sciences (W2A) & ASsc_01-11 & 20,008 \\
4 & Academic writing technical (W2A) & ATec_01-11 & 20,066 \\
5 & Administrative/Instructive writing (W2D) & adm_01-30 & 19,992 \\
6 & Business letters (W1B) & bl_01-93 & 30,142 \\
7 & Editorials (W2F) & ed_01-28 & 20,013 \\
8 & Exams (W1A) & ex_01-54 & 20,211 \\
9 & Novels (W2F) & nov_01-20 & 40,031 \\
10 & Popular writing humanities (W2B) & PHum_01-20 & 20,016 \\
11 & Popular writing natural sciences (W2B) & PNsc_01-19 & 20,037 \\
12 & Popular writing social sciences (W2B) & PSsc_01-15 & 20,022 \\
13 & Popular writing technology (W2B) & PTec_01-33 & 20,069 \\
14 & Press reportage (W2C) & pr_01-69 & 40,073 \\
15 & Instructive writing/skills and hobbies (W2D) & SkHo_01-25 & 20,007 \\
16 & Social letters (W1B) & sl_01-48 & 30,141 \\
17 & Students essays (W1A) & ess_01-12 & 19,997 \\
& Total & & 400,796 \\
\hline
\end{tabular}

(b)

\begin{tabular}{cccc}
\hline S/N & Text Type & File Name \& Number & Words \\
\hline 1 & Broadcast discussion (S1B) & bdis_01-26 & 40,290 \\
2 & Broadcast interviews (S1B) & bint_01-10 & 20,356 \\
3 & Broadcast news (S2B) & bnew_01-40 & 40,916 \\
4 & Broadcast talks (S2B) & btal_01-43 & 40,138 \\
5 & Business transactions (S1B) & btr_01-11 & 20,732 \\
6 & Class lessons (S1B) & les_01-14 & 41,394 \\
7 & Commentaries (S2A) & com_01-56 & 40,770 \\
8 & Conversations (S1A) & con_01-67 & 180,789 \\
9 & Cross-examinations (S1B) & cr_01-10 & 20,486 \\
10 & Demonstrations (S2A) & dem_01-14 & 20,594 \\
11 & Legal presentations (S2A) & leg_01-14 & 20,481 \\
12 & Non-broadcast talks (S2B) & nbtal_01-10 & 20,156 \\
13 & Parliamentary debates (S1B) & parl_01-20 & 20,161 \\
14 & Phone calls (S1A) & ph_01-07 & 20,624 \\
15 & Unscripted speeches (S2A) & unsp_01-50 & 61,699 \\
& Total & & 609,586 \\
\hline
\end{tabular}


Table 2. Frequency distribution of the PNP-constructions in the written component of ICE-Nigeria.

\begin{tabular}{|c|c|c|c|c|c|c|c|c|c|c|c|c|c|c|c|c|c|c|c|c|}
\hline $\mathrm{S} / \mathrm{N}$ & $\begin{array}{l}\text { Text Types } \\
\text { PNP-Forms }\end{array}$ & $\begin{array}{c}1 \\
\text { AHum }\end{array}$ & $\begin{array}{c}2 \\
\text { ANsc }\end{array}$ & $\begin{array}{c}3 \\
\text { ASsc }\end{array}$ & $\begin{array}{c}4 \\
\text { ATec }\end{array}$ & $\begin{array}{c}5 \\
\text { adm }\end{array}$ & $\begin{array}{c}6 \\
\mathrm{bl}\end{array}$ & $\begin{array}{c}7 \\
\text { ed }\end{array}$ & $\begin{array}{c}8 \\
\text { ex }\end{array}$ & $\begin{array}{c}9 \\
\text { nov }\end{array}$ & $\begin{array}{c}10 \\
\text { PHum }\end{array}$ & $\begin{array}{c}11 \\
\text { PNsc }\end{array}$ & $\begin{array}{c}12 \\
\text { PSsc }\end{array}$ & $\begin{array}{c}13 \\
\text { PTec }\end{array}$ & $\begin{array}{l}14 \\
\operatorname{Pr}\end{array}$ & $\begin{array}{c}15 \\
\text { SkHO }\end{array}$ & $\begin{array}{c}16 \\
\mathrm{sl}\end{array}$ & $\begin{array}{l}17 \\
\text { ess }\end{array}$ & Total & $\begin{array}{l}\text { Freq. } \\
\text { pmw }\end{array}$ \\
\hline 1 & in terms of & 6 & 5 & 4 & 7 & 1 & 2 & 1 & 5 & 1 & 4 & 0 & 0 & 6 & 2 & 0 & 1 & 12 & 58 & 145 \\
\hline 2 & in addition to & 1 & 5 & 2 & 1 & 2 & 0 & 1 & 2 & 1 & 1 & 1 & 0 & 1 & 4 & 0 & 1 & 3 & 26 & 65 \\
\hline 3 & in spite of & 1 & 2 & 3 & 0 & 1 & 0 & 0 & 1 & 5 & 1 & 1 & 1 & 0 & 1 & 3 & 0 & 3 & 23 & 57 \\
\hline 4 & in line with & 0 & 0 & 2 & 1 & 1 & 2 & 0 & 0 & 0 & 1 & 0 & 0 & 0 & 7 & 0 & 0 & 2 & 16 & 40 \\
\hline 5 & with respect to & 0 & 0 & 0 & 1 & 10 & 1 & 0 & 0 & 0 & 0 & 1 & 0 & 0 & 0 & 0 & 2 & 0 & 15 & 37 \\
\hline 6 & in accordance with & 1 & 0 & 0 & 0 & 7 & 4 & 0 & 1 & 0 & 1 & 0 & 0 & 0 & 0 & 0 & 0 & 0 & 14 & 34 \\
\hline 7 & in view of & 2 & 0 & 2 & 0 & 3 & 2 & 0 & 1 & 1 & 0 & 0 & 0 & 0 & 3 & 0 & 0 & 0 & 14 & 34 \\
\hline 8 & on behalf of & 0 & 0 & 0 & 0 & 2 & 5 & 0 & 3 & 0 & 0 & 0 & 0 & 0 & 1 & 0 & 2 & 0 & 13 & 32 \\
\hline 9 & in touch with & 0 & 0 & 0 & 0 & 0 & 1 & 0 & 0 & 0 & 0 & 0 & 0 & 0 & 0 & 1 & 11 & 0 & 13 & 32 \\
\hline 10 & in front of & 0 & 0 & 0 & 0 & 0 & 0 & 0 & 0 & 6 & 0 & 0 & 3 & 0 & 0 & 3 & 0 & 0 & 12 & 30 \\
\hline 11 & in respect of & 0 & 0 & 0 & 0 & 9 & 1 & 0 & 0 & 0 & 0 & 0 & 0 & 0 & 1 & 0 & 0 & 0 & 11 & 27 \\
\hline 12 & in relation to & 2 & 1 & 2 & 0 & 1 & 0 & 2 & 0 & 0 & 0 & 0 & 1 & 0 & 0 & 0 & 0 & 2 & 11 & 27 \\
\hline 13 & in favour of & 0 & 0 & 1 & 0 & 0 & 3 & 1 & 0 & 0 & 2 & 0 & 0 & 0 & 1 & 0 & 0 & 1 & 9 & 22 \\
\hline 14 & by virtue of & 1 & 0 & 2 & 0 & 0 & 0 & 1 & 0 & 0 & 0 & 0 & 0 & 0 & 1 & 1 & 0 & 1 & 7 & 18 \\
\hline 15 & with regard to & 2 & 0 & 0 & 1 & 1 & 1 & 0 & 1 & 0 & 0 & 1 & 0 & 0 & 1 & 0 & 0 & 1 & 9 & 22 \\
\hline 16 & in response to & 0 & 0 & 1 & 0 & 0 & 1 & 0 & 1 & 0 & 0 & 0 & 0 & 2 & 1 & 0 & 0 & 0 & 6 & 15 \\
\hline 17 & with reference to & 2 & 0 & 0 & 0 & 0 & 2 & 0 & 0 & 0 & 0 & 0 & 0 & 0 & 0 & 0 & 0 & 0 & 4 & 10 \\
\hline 18 & in honour of & 0 & 0 & 0 & 0 & 0 & 0 & 0 & 0 & 2 & 0 & 0 & 0 & 0 & 2 & 0 & 0 & 0 & 4 & 10 \\
\hline 19 & in lieu of & 0 & 0 & 0 & 0 & 0 & 2 & 0 & 0 & 0 & 0 & 0 & 0 & 0 & 0 & 0 & 0 & 1 & 3 & 8 \\
\hline 20 & in conjunction with & 1 & 0 & 0 & 0 & 0 & 0 & 1 & 0 & 0 & 0 & 0 & 0 & 1 & 0 & 0 & 0 & 0 & 3 & 8 \\
\hline 21 & in connection with & 0 & 0 & 0 & 0 & 0 & 0 & 0 & 0 & 0 & 0 & 0 & 0 & 0 & 2 & 0 & 0 & 0 & 2 & 5 \\
\hline 22 & in support of & 0 & 0 & 0 & 0 & 0 & 1 & 1 & 0 & 0 & 0 & 0 & 0 & 0 & 0 & 0 & 0 & 0 & 2 & 5 \\
\hline 23 & in recognition of & 0 & 0 & 0 & 0 & 0 & 0 & 0 & 0 & 1 & 0 & 0 & 0 & 0 & 1 & 0 & 0 & 0 & 2 & 5 \\
\hline 24 & in consonance with & 2 & 0 & 0 & 0 & 0 & 0 & 0 & 0 & 0 & 0 & 0 & 0 & 0 & 0 & 0 & 0 & 0 & 2 & 5 \\
\hline 25 & in charge of & 0 & 0 & 1 & 0 & 0 & 0 & 0 & 0 & 0 & 0 & 0 & 0 & 0 & 0 & 0 & 1 & 0 & 2 & 5 \\
\hline 26 & by means of & 0 & 0 & 1 & 0 & 0 & 0 & 0 & 0 & 0 & 0 & 0 & 0 & 0 & 0 & 0 & 0 & 0 & 1 & 3 \\
\hline 27 & in search of & 0 & 0 & 0 & 0 & 0 & 0 & 0 & 0 & 0 & 0 & 0 & 0 & 0 & 0 & 1 & 0 & 0 & 1 & 3 \\
\hline 28 & in excess of & 0 & 1 & 0 & 0 & 0 & 0 & 0 & 0 & 0 & 0 & 0 & 0 & 0 & 0 & 0 & 0 & 0 & 1 & 3 \\
\hline 29 & in place of & 0 & 0 & 0 & 0 & 0 & 0 & 1 & 0 & 0 & 0 & 0 & 0 & 0 & 0 & 0 & 0 & 0 & 1 & 3 \\
\hline 30 & in consultation with & 0 & 0 & 0 & 0 & 1 & 0 & 0 & 0 & 0 & 0 & 0 & 0 & 0 & 0 & 0 & 0 & 0 & 1 & 3 \\
\hline 31 & in pursuance of & 0 & 0 & 0 & 0 & 1 & 0 & 0 & 0 & 0 & 0 & 0 & 0 & 0 & 0 & 0 & 0 & 0 & 1 & 3 \\
\hline 32 & in form of & 1 & 0 & 0 & 0 & 0 & 0 & 0 & 0 & 0 & 1 & 0 & 0 & 0 & 0 & 0 & 0 & 0 & 2 & 5 \\
\hline 33 & in return for & 0 & 0 & 0 & 0 & 0 & 0 & 0 & 0 & 0 & 0 & 0 & 0 & 0 & 1 & 0 & 0 & 0 & 1 & 3 \\
\hline 34 & in adherence to & 0 & 0 & 0 & 0 & 0 & 0 & 0 & 0 & 0 & 0 & 0 & 0 & 0 & 1 & 0 & 0 & 0 & 1 & 3 \\
\hline 35 & in preparation for & 0 & 0 & 0 & 0 & 0 & 0 & 0 & 0 & 0 & 0 & 0 & 0 & 0 & 1 & 0 & 0 & 0 & 1 & 3 \\
\hline 36 & in order for & 0 & 0 & 1 & 0 & 0 & 0 & 0 & 0 & 0 & 0 & 0 & 0 & 0 & 0 & 0 & 0 & 0 & 1 & 3 \\
\hline 37 & with support from & 1 & 0 & 0 & 0 & 0 & 0 & 0 & 0 & 0 & 0 & 0 & 0 & 0 & 0 & 0 & 0 & 0 & 1 & 3 \\
\hline 38 & by order of & 0 & 0 & 0 & 0 & 1 & 0 & 0 & 0 & 0 & 0 & 0 & 0 & 0 & 0 & 0 & 0 & 0 & 1 & 3 \\
\hline 39 & without prejudice to & 0 & 0 & 0 & 0 & 1 & 0 & 0 & 0 & 0 & 0 & 0 & 0 & 0 & 0 & 0 & 0 & 0 & 1 & 3 \\
\hline 40 & in contrast with & 0 & 0 & 0 & 0 & 0 & 0 & 0 & 1 & 0 & 0 & 0 & 0 & 0 & 0 & 0 & 0 & 0 & 1 & 3 \\
\hline 41 & in alliance with & 1 & 0 & 0 & 0 & 0 & 0 & 0 & 0 & 0 & 0 & 0 & 0 & 0 & 0 & 0 & 0 & 0 & 1 & 3 \\
\hline 42 & in preference to & 1 & 0 & 0 & 0 & 0 & 0 & 0 & 0 & 0 & 0 & 0 & 0 & 0 & 0 & 0 & 0 & 0 & 1 & 3 \\
\hline 43 & in memory of & 0 & 0 & 0 & 0 & 0 & 1 & 0 & 0 & 0 & 0 & 0 & 0 & 0 & 0 & 0 & 0 & 0 & 1 & 3 \\
\hline 44 & in conformity with & 0 & 0 & 0 & 0 & 1 & 0 & 0 & 0 & 0 & 0 & 0 & 0 & 0 & 0 & 0 & 0 & 0 & 1 & 3 \\
\hline 45 & in light of & 0 & 0 & 0 & 0 & 0 & 0 & 0 & 0 & 0 & 0 & 0 & 0 & 0 & 0 & 0 & 0 & 1 & 1 & 3 \\
\hline 46 & in behalf of & 0 & 0 & 0 & 0 & 0 & 1 & 0 & 0 & 0 & 0 & 0 & 0 & 0 & 0 & 0 & 0 & 0 & 1 & 3 \\
\hline \multirow[t]{2}{*}{47} & in times of & 1 & 0 & 0 & 0 & 0 & 0 & 0 & 0 & 0 & 0 & 0 & 0 & 0 & 0 & 0 & 0 & 0 & 1 & 3 \\
\hline & Total & 25 & 14 & 21 & 11 & 43 & 31 & 9 & 16 & 17 & 11 & 4 & 5 & 10 & 31 & 10 & 18 & 27 & 303 & 755 \\
\hline
\end{tabular}


Table 3. Frequency distribution of the PNP-constrictions in the spoken component of ICE-Nigeria.

\begin{tabular}{|c|c|c|c|c|c|c|c|c|c|c|c|c|c|c|c|c|c|c|}
\hline $\mathrm{S} / \mathrm{N}$ & $\begin{array}{l}\text { Text Types } \\
\text { PNP-Forms }\end{array}$ & $\begin{array}{c}18 \\
\text { bdis }\end{array}$ & $\begin{array}{c}19 \\
\text { bint }\end{array}$ & $\begin{array}{c}20 \\
\text { bnew }\end{array}$ & $\begin{array}{c}21 \\
\text { btal }\end{array}$ & $\begin{array}{l}22 \\
\text { btr }\end{array}$ & $\begin{array}{l}23 \\
\text { les }\end{array}$ & $\begin{array}{c}24 \\
\text { com }\end{array}$ & $\begin{array}{c}25 \\
\text { con }\end{array}$ & $\begin{array}{l}26 \\
\mathrm{cr}\end{array}$ & $\begin{array}{c}27 \\
\text { dem }\end{array}$ & $\begin{array}{l}28 \\
\text { leg }\end{array}$ & $\begin{array}{c}29 \\
\text { nbtal }\end{array}$ & $\begin{array}{c}30 \\
\text { parl }\end{array}$ & $\begin{array}{l}31 \\
\text { ph }\end{array}$ & $\begin{array}{c}32 \\
\text { unsp }\end{array}$ & Total & $\begin{array}{l}\text { Freq. } \\
\text { pmw }\end{array}$ \\
\hline 1 & in terms of & 10 & 9 & 0 & 2 & 3 & 7 & 10 & 16 & 2 & 0 & 1 & 3 & 0 & 5 & 19 & 87 & 143 \\
\hline 2 & on behalf of & 0 & 0 & 3 & 2 & 3 & 0 & 1 & 0 & 0 & 0 & 1 & 1 & 0 & 0 & 7 & 18 & 30 \\
\hline 3 & in favour of & 1 & 0 & 0 & 1 & 1 & 0 & 1 & 1 & 0 & 0 & 2 & 0 & 12 & 0 & 0 & 19 & 31 \\
\hline 4 & in spite of & 1 & 0 & 0 & 1 & 0 & 2 & 1 & 0 & 1 & 0 & 1 & 2 & 1 & 0 & 3 & 13 & 21 \\
\hline 5 & in addition to & 0 & 0 & 0 & 0 & 4 & 1 & 1 & 2 & 0 & 0 & 0 & 3 & 0 & 0 & 1 & 12 & 20 \\
\hline 6 & in front of & 1 & 0 & 0 & 0 & 0 & 1 & 4 & 2 & 2 & 1 & 0 & 0 & 0 & 0 & 2 & 13 & 21 \\
\hline 7 & in respect of & 0 & 0 & 0 & 0 & 0 & 0 & 0 & 0 & 6 & 0 & 3 & 0 & 1 & 0 & 1 & 11 & 18 \\
\hline 8 & in accordance with & 1 & 0 & 0 & 0 & 0 & 0 & 0 & 0 & 0 & 0 & 2 & 1 & 5 & 0 & 0 & 9 & 15 \\
\hline 9 & in line with & 1 & 0 & 0 & 1 & 0 & 0 & 1 & 3 & 0 & 0 & 0 & 1 & 3 & 0 & 0 & 10 & 15 \\
\hline 10 & in view of & 0 & 0 & 0 & 0 & 1 & 0 & 0 & 0 & 0 & 0 & 3 & 0 & 1 & 0 & 2 & 7 & 12 \\
\hline 11 & in contact with & 0 & 0 & 0 & 0 & 0 & 0 & 0 & 0 & 2 & 0 & 0 & 0 & 0 & 2 & 2 & 6 & 10 \\
\hline 12 & with regard to & 3 & 0 & 1 & 0 & 0 & 0 & 0 & 0 & 0 & 0 & 0 & 0 & 0 & 0 & 3 & 7 & 12 \\
\hline 13 & in support of & 0 & 0 & 0 & 0 & 0 & 1 & 0 & 0 & 0 & 0 & 0 & 1 & 3 & 0 & 1 & 6 & 10 \\
\hline 14 & in form of & 0 & 0 & 0 & 0 & 0 & 4 & 0 & 1 & 0 & 0 & 0 & 0 & 0 & 0 & 1 & 6 & 10 \\
\hline 15 & in touch with & 0 & 0 & 0 & 0 & 0 & 0 & 0 & 4 & 0 & 0 & 0 & 0 & 0 & 1 & 1 & 6 & 10 \\
\hline 16 & with respect to & 0 & 0 & 0 & 0 & 2 & 0 & 0 & 0 & 1 & 0 & 0 & 0 & 0 & 0 & 2 & 5 & 8 \\
\hline 17 & by virtue of & 0 & 0 & 0 & 0 & 1 & 0 & 0 & 0 & 1 & 0 & 2 & 0 & 1 & 0 & 0 & 5 & 8 \\
\hline 18 & in relation to & 0 & 0 & 0 & 0 & 0 & 0 & 1 & 0 & 0 & 0 & 0 & 0 & 0 & 0 & 2 & 3 & 5 \\
\hline 19 & in excess of & 2 & 1 & 0 & 0 & 0 & 0 & 0 & 0 & 0 & 0 & 0 & 0 & 0 & 0 & 0 & 3 & 5 \\
\hline 20 & in honour of & 0 & 0 & 1 & 0 & 1 & 0 & 1 & 0 & 0 & 0 & 0 & 0 & 0 & 0 & 0 & 3 & 5 \\
\hline 21 & in collaboration with & 0 & 0 & 0 & 0 & 0 & 0 & 0 & 0 & 0 & 0 & 0 & 1 & 0 & 1 & 0 & 2 & 3 \\
\hline 22 & in response to & 0 & 0 & 0 & 0 & 0 & 0 & 1 & 0 & 0 & 0 & 0 & 0 & 0 & 0 & 1 & 2 & 3 \\
\hline 23 & in connection with & 2 & 0 & 0 & 0 & 0 & 0 & 0 & 0 & 0 & 0 & 0 & 0 & 0 & 0 & 0 & 2 & 3 \\
\hline 24 & in place of & 0 & 0 & 0 & 0 & 0 & 0 & 0 & 1 & 0 & 0 & 0 & 0 & 1 & 0 & 0 & 2 & 3 \\
\hline 25 & on top of & 0 & 0 & 1 & 0 & 0 & 0 & 0 & 0 & 0 & 0 & 0 & 0 & 0 & 0 & 1 & 2 & 3 \\
\hline 26 & in conjunction with & 0 & 0 & 0 & 0 & 0 & 0 & 0 & 1 & 0 & 0 & 0 & 0 & 1 & 0 & 0 & 2 & 3 \\
\hline 27 & in respect to & 0 & 0 & 0 & 0 & 0 & 0 & 0 & 0 & 1 & 0 & 0 & 0 & 0 & 0 & 1 & 2 & 3 \\
\hline 28 & in recognition of & 1 & 0 & 0 & 0 & 0 & 0 & 0 & 0 & 0 & 0 & 0 & 0 & 0 & 0 & 0 & 1 & 2 \\
\hline 29 & in comparison with & 0 & 1 & 0 & 0 & 0 & 0 & 0 & 0 & 0 & 0 & 0 & 0 & 0 & 0 & 0 & 1 & 2 \\
\hline 30 & in tune with & 0 & 0 & 0 & 1 & 0 & 0 & 0 & 0 & 0 & 0 & 0 & 0 & 0 & 0 & 0 & 1 & 2 \\
\hline 31 & in absence of & 0 & 0 & 0 & 0 & 0 & 1 & 0 & 0 & 0 & 0 & 0 & 0 & 0 & 0 & 0 & 1 & 2 \\
\hline 32 & in face of & 0 & 0 & 0 & 0 & 0 & 0 & 1 & 0 & 0 & 0 & 0 & 0 & 0 & 0 & 0 & 1 & 2 \\
\hline 33 & in opposition to & 0 & 0 & 0 & 0 & 0 & 0 & 0 & 0 & 0 & 0 & 1 & 0 & 0 & 0 & 0 & 1 & 2 \\
\hline 34 & with reference to & 0 & 0 & 0 & 0 & 0 & 0 & 0 & 0 & 0 & 0 & 1 & 0 & 0 & 0 & 0 & 1 & 2 \\
\hline 35 & in pursuit of & 0 & 0 & 0 & 0 & 0 & 0 & 0 & 0 & 0 & 0 & 0 & 0 & 0 & 0 & 1 & 1 & 2 \\
\hline 36 & in association with & 0 & 0 & 0 & 0 & 0 & 0 & 0 & 0 & 0 & 0 & 0 & 0 & 0 & 0 & 1 & 1 & 2 \\
\hline 37 & in conformity with & 0 & 0 & 0 & 0 & 0 & 0 & 0 & 0 & 0 & 0 & 0 & 0 & 1 & 0 & 0 & 1 & 2 \\
\hline 38 & in contrast with & 0 & 0 & 0 & 0 & 0 & 0 & 0 & 1 & 0 & 0 & 0 & 0 & 0 & 0 & 0 & 1 & 2 \\
\hline 39 & at variance with & 0 & 0 & 0 & 0 & 0 & 0 & 0 & 0 & 0 & 0 & 0 & 0 & 1 & 0 & 0 & 1 & 2 \\
\hline 40 & in reference to & 0 & 0 & 0 & 0 & 0 & .0 & 0 & 0 & 0 & 0 & 0 & 0 & 1 & 0 & 0 & 1 & 2 \\
\hline 41 & in compliance with & 0 & 0 & 0 & 0 & 0 & 0 & 0 & 0 & 0 & 0 & 0 & 0 & 1 & 0 & 0 & 1 & 2 \\
\hline 42 & in consonance with & 1 & 0 & 0 & 0 & 0 & 0 & 0 & 0 & 0 & 0 & 0 & 0 & 0 & 0 & 0 & 1 & 2 \\
\hline 43 & in follower-ship with & 1 & 0 & 0 & 0 & 0 & 0 & 0 & 0 & 0 & 0 & 0 & 0 & 0 & 0 & 0 & 1 & 2 \\
\hline 44 & with view of & 0 & 0 & 0 & 0 & 0 & 0 & 0 & 0 & 0 & 0 & 1 & 0 & 0 & 0 & 0 & 1 & 2 \\
\hline 45 & in charge of & 0 & 0 & 0 & 0 & 0 & 0 & 0 & 1 & 0 & 0 & 0 & 0 & 0 & 0 & 0 & 1 & 2 \\
\hline \multirow[t]{2}{*}{46} & in consultation with & 0 & 0 & 0 & 0 & 0 & 0 & 0 & 0 & 0 & 0 & 0 & 0 & 1 & 0 & 0 & 1 & 2 \\
\hline & Total & 25 & 11 & 6 & 8 & 16 & 17 & 23 & 32 & 16 & 1 & 18 & 13 & 34 & 9 & 52 & 282 & 464 \\
\hline
\end{tabular}


Table 4. Frequency distribution of complex prepositions in ICE-Nigeria.

\begin{tabular}{|c|c|c|c|c|c|c|}
\hline $\mathrm{S} / \mathrm{N}$ & PNP-Constructions & $\begin{array}{c}\text { Spoken } \\
\text { Component }\end{array}$ & $\begin{array}{c}\text { Written } \\
\text { Component }\end{array}$ & Total & Percentage & $\begin{array}{c}\text { Frequency } \\
\text { (pmw) }\end{array}$ \\
\hline 1 & in terms of & 87 & 58 & 145 & 25 & 144 \\
\hline 2 & in addition to & 12 & 26 & 38 & 7 & 37.6 \\
\hline 3 & in spite of & 13 & 23 & 36 & 6.3 & 35.6 \\
\hline 4 & on behalf of & 18 & 13 & 31 & 5.3 & 30.7 \\
\hline 5 & in favour of & 19 & 9 & 28 & 4.8 & 26.7 \\
\hline 6 & in line with & 10 & 16 & 26 & 4.4 & 24.7 \\
\hline 7 & in front of & 13 & 12 & 25 & 4.3 & 23.7 \\
\hline 8 & in accordance with & 9 & 14 & 23 & 3.9 & 22.7 \\
\hline 9 & in respect of & 11 & 11 & 22 & 3.8 & 21.7 \\
\hline 10 & in view of & 7 & 14 & 21 & 3.6 & 20.7 \\
\hline 11 & with respect to & 5 & 15 & 20 & 3.4 & 19.8 \\
\hline 12 & in touch with & 6 & 13 & 19 & 3.2 & 18.8 \\
\hline 13 & with regard to & 7 & 9 & 16 & 2.7 & 13.9 \\
\hline 14 & in relation to & 3 & 11 & 14 & 2.4 & 13.9 \\
\hline 15 & by virtue of & 5 & 7 & 12 & 2 & 11.8 \\
\hline 16 & in response to & 2 & 6 & 8 & 1.4 & 7.9 \\
\hline 17 & in support of & 6 & 2 & 8 & 1.4 & 7.9 \\
\hline 18 & in form of & 6 & 1 & 7 & 1.2 & 6.9 \\
\hline 19 & in honour of & 3 & 4 & 7 & 1.2 & 6.9 \\
\hline 20 & in contact with & 6 & 0 & 6 & 1 & 5.9 \\
\hline 21 & with reference to & 1 & 4 & 5 & 0.9 & 4.9 \\
\hline 22 & in conjunction with & 2 & 3 & 5 & 0.9 & 4.9 \\
\hline 23 & in connection with & 2 & 2 & 4 & 0.7 & 3.9 \\
\hline 24 & in excess of & 3 & 1 & 4 & 0.7 & 3.9 \\
\hline 25 & in lieu of & 0 & 3 & 3 & 0.5 & 2.9 \\
\hline 26 & in recognition of & 1 & 2 & 3 & 0.5 & 2.9 \\
\hline 27 & in place of & 2 & 1 & 3 & 0.5 & 2.9 \\
\hline 28 & in consonance with & 1 & 2 & 3 & 0.5 & 2.9 \\
\hline 29 & in consultation with & 1 & 1 & 2 & 0.3 & 1.98 \\
\hline 30 & in charge of & 1 & 2 & 3 & 0.3 & 1.98 \\
\hline 31 & on top of & 2 & 0 & 2 & 0.3 & 1.98 \\
\hline 32 & in collaboration with & 2 & 0 & 2 & 0.3 & 1.98 \\
\hline
\end{tabular}




\section{Continued}

\begin{tabular}{|c|c|c|c|c|c|c|}
\hline 33 & in respect to & 2 & 0 & 2 & 0.3 & 1.98 \\
\hline 34 & in contrast with & 1 & 1 & 2 & 0.3 & 1.98 \\
\hline 35 & in conformity with & 1 & 1 & 2 & 0.3 & 1.98 \\
\hline 36 & in comparison with & 1 & 0 & 1 & 0.2 & 0.99 \\
\hline 37 & in pursuance of & 0 & 1 & 1 & 0.2 & 0.99 \\
\hline 38 & in return for & 0 & 1 & 1 & 0.2 & 0.99 \\
\hline 39 & in adherence to & 0 & 1 & 1 & 0.2 & 0.99 \\
\hline 40 & in preparation for & 0 & 1 & 1 & 0.2 & 0.99 \\
\hline 41 & in memory of & 0 & 1 & 1 & 0.2 & 0.99 \\
\hline 42 & with support from & 0 & 1 & 1 & 0.2 & 0.99 \\
\hline 43 & by order of & 0 & 1 & 1 & 0.2 & 0.99 \\
\hline 44 & without prejudice to & 0 & 1 & 1 & 0.2 & 0.99 \\
\hline 45 & by means of & 0 & 1 & 1 & 0.2 & 0.99 \\
\hline 46 & in tune with & 1 & 0 & 1 & 0.2 & 0.99 \\
\hline 47 & in absence of & 1 & 0 & 1 & 0.2 & 0.99 \\
\hline 48 & in face of & 1 & 0 & 1 & 0.2 & 0.99 \\
\hline 49 & in pursuit of & 1 & 0 & 1 & 0.2 & 0.99 \\
\hline 50 & in opposition to & 1 & 0 & 1 & 0.2 & 0.99 \\
\hline 51 & in association with & 1 & 0 & 1 & 0.2 & 0.99 \\
\hline 52 & in light of & 0 & 1 & 1 & 0.2 & 0.99 \\
\hline 53 & in behalf of & 0 & 1 & 1 & 0.2 & 0.99 \\
\hline 54 & at variance with & 1 & 0 & 1 & 0.2 & 0.99 \\
\hline 55 & in reference to & 1 & 0 & 1 & 0.2 & 0.99 \\
\hline 56 & in compliance with & 1 & 0 & 1 & 0.2 & 0.99 \\
\hline 57 & in search of & 0 & 1 & 1 & 0.2 & 0.99 \\
\hline 58 & with view of & 1 & 0 & 1 & 0.2 & 0.99 \\
\hline 59 & in follower-ship with & 1 & 0 & 1 & 0.2 & 0.99 \\
\hline 60 & in alliance with & 0 & 1 & 1 & 0.2 & 0.99 \\
\hline 61 & in preference to & 0 & 1 & 1 & 0.2 & 0.99 \\
\hline 62 & in times of & 0 & 1 & 1 & 0.2 & 0.99 \\
\hline \multirow[t]{3}{*}{63} & in order for & 0 & 1 & 1 & 0.2 & 0.99 \\
\hline & Total & 282 & 303 & 585 & 100 & 579 \\
\hline & Percentage & 48 & 52 & 100 & & \\
\hline
\end{tabular}


PNP-construction represents at the different levels (which is a measure of PNP-construction density in different natural language text types). This was done by dividing the number of occurrence of a given form (or the total PNPconstruction occurrence for each level) with the size of its bearing corpus and multiplying by hundred. Second, I calculated the frequency per million words (pmw) of each form (or all the forms therein) at the different levels by dividing same with the number of words that consist the appropriate corpus and multiplying by $1,000,000$. These calculations facilitated subsequent comparison at the different levels, which forms the third stage of the analysis. For example, I compared the spoken and written components with a view to determining variations in the rate of occurrence (if any) and account for same. I also examined the text types in order to identify the type and frequency of forms therein and provide explanations for differences in patterning. Fourth, I classified all the $63 \mathrm{CPs}$ of the PNP-construction into syntactic categories in order to determine which variants (e.g. in + noun + of) are more frequent, identified those that are clauseinitially and those that are deviant, and accounted for differences in their manifestations. Fifth, I classified all the forms into semantic groups based on Klègr's (1997) categorisation of CP meanings into seven major (e.g. contingency) and twenty-five minor (e.g. purpose-goal) subsets. Thereafter, I determined the frequency of each meaning type and that of the forms indicating them and expressed same in percentages. Finally, based on the relevant aspects of Hoffmann (2005) study's outcome, I compared and contrasted the occurrence and distribution of CPs of the PNP-construction in non-native (ICE-Nigeria) and native (BNC) English and accounted for the similarities and differences.

\section{Results and Discussion}

This section presents and discusses results of the analysis of the occurrence and distribution of CPs of the PNP-construction in Nigerian English based on ICE-Nigeria. It is in five main parts, namely general distribution, formal features, textual manifestations, semantic patterns, and comparison. Sentential extracts are provided and the forms under focus are italicised. Copied directly from the source texts and pasted as appropriate, each extract is accompanied with information on corpus name (ICE-Nigeria), text type (e.g. ess), file number (e.g. _01), and line number (e.g. L15) enclosed in brackets.

\subsection{General Distribution}

Since ICE-Nigeria has both spoken and written components, it becomes logical to begin this presentation of the frequency distribution of the PNP-constructions with them, followed by the gamut of ICE-Nigeria.

\subsubsection{The Written Component}

Table 2 displays the distribution of CPs of the PNP-construction in the written component of ICE-Nigeria and shows that there are 47 forms with 303 occurrences. Since the written corpus comprises 400,796 words it follows that the forms' 
rate of occurrence was $756 \mathrm{pmw}$. Only in terms of had a frequency of $145 \mathrm{pmw}$ with its 58 occurrences, which was the highest. The closest forms in addition to and in spite of recorded a frequency of occurrence of 65 and 57 pmw respectively. Rates for the rest are in the range of 40 - 49 (1: in line with), 30 - 39 (6, e.g. in view of), 20 - 29 (3, e.g. in respect of), 10 - 19 (5, e.g. with reference to), and 1 - 9 (29, e.g. in consonance with). Twenty forms appeared once only at 3 pmw (e.g. in adherence to). Here are sentential extracts.

(1a) The study then computes interference in the locations in terms of the effective transmission loss and compares the results obtained with Ile-Ife, Nigeria.

(ICE-Nigeria, ATec_06 L90)

(1b) In spite of this, more avenues for sourcing need to be exploited to meet the group demand for financial assistance by the numerous qualified students desiring to further their education.

(ICE-Nigeria, ASsc_05 L100)

(1c) Your programme of visit is very much in line with the desire of our university for collaboration and exchange programmes between staff and students of different universities.

(ICE-Nigeria, bl_24 L6)

\subsubsection{The Spoken Component}

Table 3 presents the frequency distribution of CPs of the PNP-construction in the spoken component of ICE-Nigeria. There were 46 forms with 282 occurrences as already stated. This gives a frequency of $464 \mathrm{pmw}$, given that the corpus size is 609,586 words. The most frequent PNP-construction was in terms of; its 87 occurrences translate to a rate of 143 pmw. On behalf of and in favour of distantly followed with 18 occurrences each at a frequency of $30 \mathrm{pmw}$. The remaining 43 forms are in the range of 20 - 29 (3, e.g. in spite of), 10 - 19 (9, e.g. in front of ), and 1 - 9 (31, e.g. with respect to). Nineteen forms featured once only at the rate of $2 \mathrm{pmw}$ (e.g., in recognition of).

The extracts that follow illustrate PNP-constructions in the spoken component of ICE-Nigeria.

(2a) And we're still looking forward for better things to happen in Oshodi in terms of development of the area.

(ICE-Nigeria, bint_03 L415)

(2b) It is our tradition that the the governor receives or holds a dinner in honour of the association.

(ICE-Nigeria, btr_05 L483)

(2c) Erm a colleague who sits right in front of me came out out with this book some years back.

(ICE-Nigeria, unsp_09 L64)

\subsubsection{The ICE-Nigeria Gamut}

Sixty-three CPs of the PNP-construction occurred 585 times in ICE-Nigeria. This gives a mean occurrence of 9 per form and a frequency pmw of 579. How- 
ever, only 15 PNP-constructions were above the mean. Twenty-eight (44 percent) appeared only once, which means the forms either occurred in the spoken component only (12, e.g. in tune with) or in the written component only $(16$, e.g. in return for). Still among the low-frequency forms are those that featured thrice in the written component only (in lieu of) and those that with two occurrences in the spoken component only (in collaboration with, on top of, and in respect to). Table 4 exposes these and many more facts.

Predictably in terms of emerged the most frequent PNP-construction in ICE-Nigeria with 145 occurrences at a frequency of 144 pmw. It constitutes 25 percent of the data and was only slightly less frequent in the spoken corpus (143 pmw) and slightly more frequent in the written corpus (145 pmw). The next three high occurring forms-in addition to, in spite of, and on behalf of-were far more frequent in the written component than in the spoken component with a respective frequency pmw of 65 and 12, 57 and 21, and 34 and 30. These give respective ratios of 11:3, 5.4:2 and 5:4 in favour of the written corpus. Indeed, with the respective rates of $755 \mathrm{pmw}$ and $464 \mathrm{pmw}$ (which translate to ratio 3:2), the PNP-constructions were one-and-a-half times more frequent in the written corpus than in the spoken component. In essence, CPs of the PNP-construction occurred more frequently in written language than in spoken language. With the exception of the low-frequency forms restricted to the spoken component, there were only four other PNP-constructions whose frequency pmw was higher in the spoken component than in the written one. These are in favour of $(30 \mathrm{v} 22)$, in support of $(10 \mathrm{v} 5)$, in form of $(10 \mathrm{v} 5)$, and in excess of $(5 \mathrm{v} 3)$. Explanations for the variations in the pattern of distribution will be offered when the data is examined from the viewpoint of the different text types that constitute the corpus.

\subsection{Formal Features}

Six formal features associated with CPs of the PNP-construction in ICE-Nigeria were identified. They are syntactic variants, occurrence at clause initial, insertions, coordination, passivisation and deviations. All are examined as follows.

\subsubsection{Syntactic Variants}

Given that CPs of the PNP-construction are not known to be monochrome forms, I sought to determine which variants of the construction there were in the corpus and how syntactically productive each one was by summing up their occurrences and expressing same in percentages. As Table 5 displays, there featured 11 syntactic variants. The sequence "in + noun + of" was the most productive, constituting 37 percent of the 63 PNP-constructions and 56 percent of their 585 instantiations. The "in + noun + with" and "in + noun + to" variants distantly followed. Though it had only two representations the "on + noun + of" variant was equally productive.

\subsubsection{Occurrence at Clause Initial}

One major syntactic function of the PP is to realise the adjunct, which is nor- 
mally positioned at clause end. Because the adjunct is mobile it can occupy other positions in the clause structure including initial position. This section presents the outcome of the critical examination of the PNP-construction-headed PPs that occurred clause-initially.

Nineteen PNP-constructions headed 108 PPs positioned clause-initially as adjuncts. These represent 30 percent of the forms and 18.3 percent of their overall frequency respectively. In addition to was the most frequent. Its 20 occurrences represent 53 percent of its instantiations and 75 percent of this was in the written component. In spite of closely followed with 18 manifestations, which is half of its total occurrence. Remarkably 75 percent of the occurrence of on behalf of at clause initial was in the spoken component. The single occurrence of without prejudice to and in absence of was at initial position. There were far more PNP-constructions occurring clause-initially in the written component (70 percent) than in the spoken component of the corpus, where their distribution differed according to text type. The PNP-constructions occurring clause-initially were more frequent in Students Essays (9), Academic Natural Sciences(8), Popular Humanities (6), Editorials (6), Administrative Writing (5), and Exams(5). Four texts had no manifestations whatsoever (e.g. Press Reportage). While writers' style, subject matter and purpose may explain the variations seen, the figures generally contrast sharply with Quirk et al.'s (1985: p. 501) report that in the Survey of English Corpus PPs constitute 9.5 percent of items occurring clauseinitially and that it is 6 percent in spoken language and 12 percent in written language. While Table 6 captures the details extracts (3a)-(3e) illustrate the phenomenon.

Table 5. Syntactic variants of the PNP-constructions and their occurrences.

\begin{tabular}{|c|c|c|c|c|c|c|}
\hline $\mathrm{S} / \mathrm{N}$ & Syntactic Variants & $\mathrm{N}$ of forms & Percentage & $\mathrm{N}$ of Occurrences & Percentage & Examples \\
\hline 1 & in + noun + of & 23 & 37 & 324 & 56 & in terms of, in form of \\
\hline 2 & in + noun + with & 16 & 25.4 & 98 & 17 & in line with, in touch with \\
\hline 3 & in + noun + to & 9 & 14.2 & 68 & 12 & in relation to \\
\hline 4 & in + noun + for & 3 & 5 & 3 & 0.7 & in return for \\
\hline 5 & with + noun + to & 3 & 5 & 41 & 7 & with respect to \\
\hline 6 & by + noun + of & 3 & 5 & 14 & 2.4 & by virtue of \\
\hline 7 & with + noun + of & 1 & 1.6 & 1 & 0.2 & with support of \\
\hline 8 & without + noun + to & 1 & 1.6 & 1 & 0.2 & without prejudice to \\
\hline 9 & on + noun + of & 2 & 3.2 & 33 & 6 & on behalf of \\
\hline 10 & at + noun + with & 1 & 1.6 & 1 & 0.2 & at variance with \\
\hline \multirow[t]{2}{*}{11} & with + noun + from & 1 & 1.6 & 1 & 0.2 & with support from \\
\hline & Total & 63 & 100 & 585 & 100 & \\
\hline
\end{tabular}


Table 6. Frequency of the PNP-constructions occurring clause-initially.

\begin{tabular}{|c|c|c|c|c|c|}
\hline $\mathrm{S} / \mathrm{N}$ & Forms & $\begin{array}{c}\text { Spoken } \\
\text { Component }\end{array}$ & $\begin{array}{c}\text { Written } \\
\text { Component }\end{array}$ & Total & $\begin{array}{c}\text { Percentage of } \\
\text { Occurrence }\end{array}$ \\
\hline 1 & in addition to & 5 & 15 & 20 & 53 \\
\hline 2 & in spite of & 6 & 12 & 18 & 50 \\
\hline 3 & in terms of & 6 & 10 & 16 & 11 \\
\hline 4 & in view of & 2 & 11 & 13 & 49 \\
\hline 5 & on behalf of & 9 & 3 & 12 & 33.3 \\
\hline 6 & in line with & 0 & 5 & 5 & 20 \\
\hline 7 & in accordance with & 3 & 2 & 5 & 21 \\
\hline 8 & with respect to & 2 & 1 & 3 & 14.3 \\
\hline 9 & by virtue of & 1 & 2 & 3 & 25 \\
\hline 10 & in response to & 0 & 2 & 2 & 25 \\
\hline 11 & with regard to & 0 & 2 & 2 & 15 \\
\hline 12 & with reference to & 0 & 2 & 2 & 40 \\
\hline 13 & without prejudice to & 0 & 1 & 1 & 100 \\
\hline 14 & in relation to & 0 & 1 & 1 & 7.1 \\
\hline 15 & in consonance with & 0 & 1 & 1 & 50 \\
\hline 16 & in front of & 1 & 0 & 1 & 4.2 \\
\hline 17 & in respect to & 1 & 0 & 1 & 4.4 \\
\hline 18 & in front of & 1 & 0 & 1 & 4 \\
\hline \multirow[t]{2}{*}{19} & in absence of & 1 & 0 & 1 & 100 \\
\hline & Total & 38 & 70 & 108 & 19 \\
\hline
\end{tabular}

(3a) In accordance with the provisions of our rules we are talking about general merits and principles of this bill.

(ICE-Nigeria, parl_15 L128)

(3b) In addition to their pharmaceutical properties they are available in both oral and $\mathrm{p}$ formulations.

(ICE-Nigeria, ANsc_2 L127)

(3c) Now we go straight to business. In front of me we have some of the basic materials you can use in gift-wrapping.

(ICE-Nigeria, dem_07 L19)

(3d) By virtue of their income, they have acquired a large appetite and capacity for spending.

(ICE-Nigeria, ed_01 L18)

(3e) In spite of the lapses encountered by the earlier theories they truly serve as a stepping stone to the invention of other later theories.

(ICE-Nigeria, ess_03 L113) 


\subsubsection{Insertions}

The PNP-like constructions glossed below have determiners and epithets intervening between the first prepositional element and the noun. Two are illustrated in context.

\begin{tabular}{|c|c|c|c|c|}
\hline in a form of & 4 & in the case of & 1 & in the response to \\
\hline in the light of & 4 & in the face of & 1 & with particular reference \\
\hline to 1 & & & & \\
\hline in the form of & 4 & in the place of & 1 & in unfair comparison \\
\hline with & & & & \\
\hline in the front of & 1 & in all respect of & 1 & in the \\
\hline absence of & 2 & & & \\
\hline in the view of & & in full support of & 1 & with the exception \\
\hline of & & & & \\
\hline
\end{tabular}

(4a) The ease of pressure on the mobile platform is desirable especially in the light of fears expressed recently that too much use of mobile phones can cause cancer.

(ICE-Nigeria, PTec_07 L110)

(4b) We are here to say that we are in full support of the one man one vote.

(ICE-Nigeria, unsp_49 L5)

\subsubsection{Coordination}

There were two cases of coordination seen. The first involves PNP-constructions with a common prepositional element at the beginning but different ones at the end (in consonance... and in followership with). Though the sequences of the second example belong to the same syntactic variant, the prepositional element after the noun was omitted before the coordinating conjunction in the manner of code associated with auxiliary verbs. The difference here is that the ellipsis involves the first occurrence of the form rather than the second. Retaining the first prepositional element in the coordinated sequences would be grammatically awkward, as the context shows.

(5) In addition and without prejudice to the powers conferred by subsection $\mathrm{n}$ (2) of this section, the National Assembly shall have power to make laws with respect to the following matters.

(ICE-Nigeria, adm_01 L16)

\subsubsection{Passivisation}

The single case of passive construction involves in touch with and the aftermath of the transformation leaves the second prepositional element in the sequence (with) stranded, the nominal complement having been transposed to the front of the clause.

(6a) First of all I believe that your health is very much intact and that your family is kept in touch with constantly.

(ICE-Nigeria, sl_27 L245)

Contrast extract (6a) with its reconstructed active voice counterpart and a 
non-passive construction of the same string in (6b) and (6c) respectively. In both active voice clauses the nominal complement immediately follows the second prepositional element.

(6b) First of all, I believe that your health is very much intact and that you constantly keep in touch with your family.

(6c) In order not to lose contact with my profession while I am planning for (...) I have decided to consider any small veterinary practice where I could keep in touch with the profession.

(ICE-Nigeria, sl_28 L125)

\subsubsection{Deviations}

Three cases of deviation from PNP-construction-usage norms were recorded and they pertain to archaism, incompletion and errors as detailed below.

1) Archaism

The single incidence of archaism is in radice to (See OED, 1971: p. 2403). It is not known whether a CP exists with the noun's Present-Day English variant radish. Consider in radish to in (7a):

(7a) We have long desisted from looking at culture from enticing flowery beauty. We go in radice-Radice is a Latin word-in radice to the root and then move up to the flower, the fruit of Yoruba culture.

(ICE-Nigeria, nbtal_01 L24)

\section{2) Incompletion}

There was incompletion or what Quirk et al. (1985: p. 715) describe as "reduction in explicitness", in which the second prepositional element in the sequence was unrealised: in line... (with), in spite... (of), in terms... (of), in contact... (with), in absence... (of), in accordance... (with), in lieu... (of), and in favour... $(o f)$. While the dynamics of spoken language largely explains the others (Twothird of partial realisation occurred in speech), the clipping of of with its nominal complement in in favour... (of) is text-dictated. In favour of was dominant in Parliamentary Debates where 82 percent of its occurrence in the context of voice vote was clipped. It was similarly clipped in Business Transactions.

(7b) I do second the motion as moved by the chairman House Committee on governmental affairs. I so second. Those in favour say aye. Those against say nay. The ayes have it.

(ICE-Nigeria, parl_07 L78)

(7c) Thank you very much. Those in favour say aye ayes have it.

(ICE-Nigeria, btr 05, L357)

(7d) Oh you're in contact. Oh you're in contact

(ICE-Nigeria, ph_01 L523, 524)

(7e) Feeding arrangement or allowance in lieu at N1000 per day shall be paid for every full day of specific associate lectureship responsibility.

(ICE-Nigeria, bl_74 L63)

\section{3) Errors}

Four categories of errors occurred. The first was phonologically induced and 
it concerns the use of times for terms (4) even in Cross-examinations. This is an error resulting from poor sound discrimination (/ai/ and /3:/) and poor learning (See (7f) below). The second might have come from poor recognition of the idiomatic form as regards, which has a verb origin and which does not require a post prepositional element. Its invariable $-s$-ending must have led the writers to think it is contextually a noun, resulting in the non-existent strings as regards to, in regards to and with regards to, realised twice each. There is however an underlying commonality in their shared meaning concerning, which brings us to the third error type. This is the superfluous co-occurrence of the synonyms with regard (to) and concerning (2); it is a case of possible indecision on lexical choice. Finally, there occurred in suspect for and in relief to (once each) in Legal Presentations. The first string is straightforward because it is the second prepositional element that is faulty. Consider: in suspect of. The second string is however complex. In law, the noun relief, according to the OED (1971: p. 2480), refers to "deliverance from some hardship, burden or grievances... release from an obligation". Simply, it means the grievances or reasons for going to court. Thus, in relief to refers to the removal of the burden on its nominal complement. However, as (7f) makes clear, in relation to would have been more appropriate since the Counsel attempted a comparison between interlocutory relief and the relief sought in the substantive suit. The repeated use of the noun lexeme relief (thrice) in the context might have inadvertently influenced the stringing of the PNP-construction in question. That these sequences appeared at all is an indication of their gradual process of grammaticalization.

(7f) The just concluded census will help the government in times of future planning.

(ICE-Nigeria, ex_21 L27)

(7g) He submitted that the granting of interlocutory injunction in relief to the substantive matter and urged the court to order accelerated hearing.

(ICE-Nigeria, leg_13 L83)

\subsection{Textual Manifestations}

The distribution of the $63 \mathrm{CPs}$ of the PNP-construction with their 585 occurrences in the 32 text types that make up ICE-Nigeria is displayed in Table 7.

As Table 7 shows, Administrative Writing had the highest frequency of PNPconstruction occurrence of $2151 \mathrm{pmw}$ while Demonstrations posted the lowest (49 pmw). Three text types (9 percent) are within the class interval of 1000 1999 and these include Parliamentary Debates, the text with the second highest frequency of 1686 pmw. Sixteen text types (50 percent) fall between 500 and 999 and these include Legal Presentations (878 pmw) and Broadcast Interviews (540 pmw). Lastly, 11 text types (34 percent) represented by Skills and Hobbies (499 pmw) and Broadcast News (147 pmw), fall between 100 and 499.

It was noted earlier that some forms occurred only once whereas others featured multiple times. This is an indication that text types manifest differently 
with respect to number and frequency of forms. Two cases will suffice. Because Unscripted Speeches had more forms (19 or 30 percent) with more occurrences (52 or 9 percent), it would be thought that it would return a higher rate than Administrative Writing. But its corpus is three times larger. Though Press Reportage

Table 7. Frequency distribution of PNP-constructions in the text types.

\begin{tabular}{|c|c|c|c|c|c|c|c|}
\hline $\mathrm{S} / \mathrm{N}$ & Text Types & $\begin{array}{l}\text { Forms } \\
(\mathrm{N})\end{array}$ & Percentage & $\begin{array}{l}\text { Occurrences } \\
(\mathrm{N})\end{array}$ & Percentage & $\begin{array}{c}\text { Percentage } \\
\text { (Corpus) }\end{array}$ & $\begin{array}{l}\text { Freq. } \\
(\mathrm{pmw})\end{array}$ \\
\hline 1 & adm_01-30 & 17 & 27 & 43 & 7.3 & 0.22 & 2151 \\
\hline 2 & parl_01-20 & 15 & 24 & 34 & 5.8 & 0.2 & 1686 \\
\hline 3 & ess_01-12 & 10 & 16 & 27 & 4.6 & 0.14 & 1350 \\
\hline 4 & AHum_01-11 & 13 & 21 & 25 & 4.3 & 0.13 & 1248 \\
\hline 5 & ASsc_01-11 & 10 & 16 & 21 & 3.6 & 0.1 & 1049 \\
\hline 6 & bl_01-93 & 16 & 25 & 31 & 5.3 & 0.1 & 1028 \\
\hline 7 & leg_01-14 & 11 & 17 & 18 & 3.1 & 0.1 & 878 \\
\hline 8 & unsp_01-50 & 19 & 30 & 52 & 8.9 & 0.08 & 842 \\
\hline 9 & ex_01-54 & 9 & 14 & 16 & 2.7 & 0.08 & 791 \\
\hline 10 & cr_01-10 & 8 & 13 & 16 & 2.7 & 0.08 & 781 \\
\hline 11 & pr_01-69 & 17 & 27 & 31 & 5.3 & 0.08 & 773 \\
\hline 12 & btr_01-11 & 8 & 13 & 16 & 2.7 & 0.08 & 772 \\
\hline 13 & ANsc-01-11 & 5 & 8 & 14 & 2.4 & 0.07 & 699 \\
\hline 14 & nbtal_01-10 & 8 & 13 & 13 & 2.3 & 0.06 & 645 \\
\hline 15 & bdis_01-26 & 12 & 19 & 25 & 4.3 & 0.06 & 623 \\
\hline 16 & sl_01-48 & 6 & 10 & 18 & 3.1 & 0.06 & 597 \\
\hline 17 & com_01-56 & 11 & 17 & 23 & 3.9 & 0.06 & 564 \\
\hline 18 & PHum_01-20 & 7 & 11 & 11 & 1.9 & 0.06 & 550 \\
\hline 19 & ATec_01-33 & 5 & 8 & 11 & 1.9 & 0.06 & 548 \\
\hline 20 & bint_01-10 & 3 & 5 & 11 & 1.9 & 0.05 & 540 \\
\hline 21 & SkHo_01-25 & 6 & 10 & 10 & 1.7 & 0.05 & 499 \\
\hline 22 & PTec_01-11 & 4 & 6 & 10 & 1.7 & 0.05 & 498 \\
\hline 23 & ed_01-28 & 8 & 13 & 9 & 1.5 & 0.05 & 450 \\
\hline 24 & ph_01-07 & 4 & 6 & 9 & 1.5 & 0.04 & 436 \\
\hline 25 & nov_01-20 & 7 & 11 & 17 & 2.9 & 0.04 & 425 \\
\hline 26 & les_01-14 & 7 & 11 & 17 & 2.9 & 0.04 & 411 \\
\hline 27 & PSsc_01-15 & 3 & 5 & 5 & 0.9 & 0.03 & 249 \\
\hline 28 & PNsc_01-19 & 4 & 6 & 4 & 0.7 & 0.02 & 200 \\
\hline 29 & btal_0143 & 6 & 10 & 8 & 1.4 & 0.02 & 199 \\
\hline 30 & con_01-67 & 11 & 17 & 33 & 5.5 & 0.02 & 174 \\
\hline 31 & bnew_01-40 & 4 & 6 & 6 & 1.0 & 0.02 & 147 \\
\hline \multirow[t]{2}{*}{32} & dem_01-14 & 1 & 1.6 & 1 & 0.2 & 0.01 & 49 \\
\hline & & 63 & 100 & 585 & 100 & 0.06 & 579 \\
\hline
\end{tabular}


and Administrative Writing featured 17 forms each, there are disparities in the number of PNP-construction occurrence as the figures, 31 and 43, respectively show. This is evidence that the forms are more frequently occurring in some texts than in the others. When the factor of corpus size is brought into the picture-which is a ratio of 2:1 in favour of Press Reportage-the cause of the huge difference between both texts becomes clear.

The 585 occurrences of the $63 \mathrm{PNP}$-constructions represent 0.06 percent of the corpus. Again, the PNP-construction density differed according to each text's corpus size. Thus it was highest in Administrative Writing ( 0.22 percent) and lowest in Demonstrations (0.01 percent). Six text types (19 percent) had the same proportion as the mean (e.g. Academic Humanities). The total spectrum is glossed thus:

$\begin{array}{llll}0.01-0.05 \text { percent: } & 13 \text { text types (41 percent) } & \text { e.g. bnew }(0.02) ; & \text { ed }(0.05) \\ 0.06-0.09 \text { percent: } & 12 \text { text types (38 percent) } & \text { e.g. ex (0.08); } & \text { ANSc (0.07) } \\ 0.1-0.19 \text { percent: } & 5 \text { text types (16 percent) } & \text { e.g. bl }(0.1) & \\ 0.2 \text { Plus: } & 2 \text { text types (6 percent) } & \text { e.g. parl }(0.2) & \end{array}$

In order to more adequately explain the differences in the textual behaviour of the PNP-constructions in ICE-Nigeria, and by implication, Nigerian English, the somewhat unwieldy 32 text types were grouped into 8 domains based on shared relationships (See Table 8).

Governance \& Law posted the highest occurrence of PNP-constructions in ICE-Nigeria with a frequency of 1368 pmw-which is about half that of Education (744 pmw) and Humanities (774 pmw)-distantly followed by Business (923 pmw). The domain with the least frequency of PNP-constructions was General Interest Texts (GIT) (402 pmw), followed closely by Imaginative Writing (425 pmw) and Mass Media (442 pmw). The proportion of forms and their number of occurrences relative to the data also differed accordingly. Again, Governance \& Law had the highest (58 percent), followed by GIT (54 percent)

Table 8. The distribution of PNP-constructions across domains.

\begin{tabular}{|c|c|c|c|c|c|c|c|c|}
\hline $\mathrm{S} / \mathrm{N}$ & Domains & $\begin{array}{l}\text { Corpus } \\
\text { (Size) }\end{array}$ & $\begin{array}{l}\text { Forms } \\
(\mathrm{N})\end{array}$ & $\begin{array}{c}\% \\
(63)\end{array}$ & $\begin{array}{l}\text { Occurrences } \\
(\mathrm{N})\end{array}$ & $\begin{array}{c}\% \\
(585)\end{array}$ & $\begin{array}{c}\% \\
\text { (Corpus) }\end{array}$ & $\begin{array}{l}\text { Freq. } \\
\text { (pmw) }\end{array}$ \\
\hline 1 & Governance \& Law & 81,120 & 34 & 58 & 111 & 19 & 0.14 & 1,368 \\
\hline 2 & Business & 50,874 & 18 & 30 & 47 & 8 & 0.09 & 923 \\
\hline 3 & Humanities & 80,060 & 20 & 33.3 & 62 & 10.6 & 0.08 & 774 \\
\hline 4 & Education & 80,602 & 19 & 28 & 60 & 10.3 & 0.07 & 744 \\
\hline 5 & Science\& Technology & 80,189 & 9 & 16 & 39 & 6.7 & 0.05 & 486 \\
\hline 6 & Mass Media & 203,786 & 29 & 51 & 90 & 15.4 & 0.04 & 442 \\
\hline 7 & Imaginative Writing & 40,031 & 7 & 12.3 & 17 & 3 & 0.04 & 425 \\
\hline \multirow[t]{2}{*}{8} & General Interest Texts & 395,180 & 31 & 54 & 159 & 28 & 0.04 & 402 \\
\hline & Summary & $1,010,382$ & 63 & 100 & 585 & 100 & 0.06 & 579 \\
\hline
\end{tabular}


while Imaginative Writing had the least (12.3 percent). With respect to the number of times each form featured however, GIT was highest, accounting for 28 percent as opposed to Governance \& Law's 19 percent. Imaginative Writing presented the least ( 3 percent), followed by Science \& Technology (6.7 percent) and Business ( 8 percent). One factor explains the marked differences and this is corpus size. For example, it accounts for why GIT emerged the domain with the lowest frequency of PNP-construction occurrence despite posting 31 forms with 159 occurrences. With 395,180 words, GIT is approximately two, five, seven and ten times larger than Mass Media, Governance \& Law, Education, Humanities, Science \& Technology, and Business, and Imaginative Writing respectively. Corpus size also explains why Governance \& Law's 111 PNP-construction-occurrence represents 0.14 percent of its corpus whereas GIT's 159 amount to a mere 0.04 percent. Both domains are at an approximate ratio of 3:2 in favour of GIT.

Having made the foregoing remarks, each domain can now be examined more closely. To forestall over-exemplification, extracts illustrating the textual behaviour of the PNP-constructions shall be delayed till the consideration of meaning.

\subsubsection{Governance \& Law}

The four constituent text types of Governance \& Law with their frequency of PNP-constructions are Administrative Writing (2151), Parliamentary Debates (1686), Legal Presentations (878), and Cross-Examinations (773). Administrative Writing had the highest concentration of PNP-constructions, with its 17 forms (27 percent) and 43 occurrences representing 7.3 percent of total occurrences and 0.22 percent of the corpus respectively. The highest occurring forms in Governance \& Law were in respect of (19), in accordance with (14), in favour of (13) and with respect to (11); they posted a respective frequency pmw of 234 , 172, 160 and 135, which contrasts sharply with the 21.7, 22.7, 26.7 and 19.8 of ICE-Nigeria. Indeed, with respect to and in favour of were almost four- and three-times more frequent in Administrative Writing and Parliamentary Debates with their respective rates of 500 and 496 pmw. In accordance with was more frequent in Administrative Writing (350 pmw) and Parliamentary Debates (242 pmw) while in respect of was more recurring in Administrative Writing (450 pmw) and Cross-examinations (230 pmw). The high frequency of in respect of and with respect to provoked an investigation into the five other PNPconstructions semantically indicating respect. They aggregated 33 occurrences at the rate of $407 \mathrm{pmw}$, which is instructive. Indeed in respect of s 19 occurrences in Government \& Law represent 86 percent of its total occurrence while with respect to' $\mathrm{s}$ is 55 percent. These figures contrast sharply with the 49 -pmw occurrence of in terms of whose low frequency is partly because the domain is generically a sample of formal language with minimal tolerance for hesitation (In terms of was absent in Parliamentary Debates). The relatively high incidence of in favour of and the rest is because they are part of the genres' register. Low- 
frequency PNP-constructions that are also text-selective are in pursuance of, without prejudice to, by order of, in compliance with, at variance with, by virtue of, and in opposition to.

\subsubsection{Business}

Business had the second highest occurrence of PNP-constructions with 18 forms (30 percent) featuring 47 times (8 percent). This represents 0.09 percent of the corpus-which is 50 percent higher than the mean-and translates to a frequency of 923 pmw. Business Letters and Business Transactions are its only text types and they featured PNP-constructions at 1028 pmw and 772 pmw respectively. There were 8 forms in Business Transactions and 16 in Business Letters, and only by virtue of and in honour of did not also occur in the latter. This disparity shows even in the forms' frequency of occurrence. For example, on behalf of - the most frequent form (176 pmw)-had two-third of its occurrence in Business Letters. Another is in favour of, only 25 percent of which was in Business Transactions. Three forms with presence in Business Letters only are in accordance with, in lieu of, and in line with. Although some forms were genre-specific there was no dominance, as the relative prominence of in addition to in Business Transactions (79 pmw) was stylistic.

\subsubsection{Humanities}

Humanities' 20 (33.3 percent) PNP-constructions with 62 (9.6\%) manifestations represent 0.08 percent of its corpus, featuring at a frequency of 774 pmw. Its constituent text types-Academic Humanities (Arts), Academic Social Sciences, Popular Humanities (Arts), and Popular Social Sciences-recorded rates of 1248, 1049, 550 and 249 pmw respectively. The proportion of their individual corpus that the 25 ( 43 percent), 21 ( 3.6 percent), 11 ( 1.9 percent) and 5 ( 0.9 percent) PNP-construction occurrences represent is respectively $0.13,0.1,0.06$ and 0.03 percent. As the enclosed figures respectively show, the rates and proportions were almost three times higher in Academic Writing (1149/0.12 percent) than in Popular Writing (400/0.04 percent) and were slightly higher in Arts (899/0.09) than in Social Sciences (650/0.07 percent). In terms of was again the most frequent PNP-construction (175 pmw), and was far more frequent in Arts (250 pmw) than in Social Sciences (100 pmw). In sharp contrast by means of recorded a frequency pmw of 13 . Four other forms of note are in spite of $(75 \mathrm{pmw})$, in relation to $(63 \mathrm{pmw})$, in addition to $(50 \mathrm{pmw})$, in view of $(50 \mathrm{pmw})$, and in front of (38 pmw).

\subsubsection{Education}

In contrast to Education's 744 pmw PNP-construction-frequency, its consisting text types-Students Essays, Exams and Class Lessons-respectively recorded 1350, 791 and 411 pmw. Students Essays featured 10 forms (16 percent) with 27 occurrences (4.6 percent) representing 0.14 percent of its own corpus while Exams and Class Lessons' figures for the same parameters were 9 (14 percent) and 7 (11 percent), 16 (2.7 percent) and 17 (2.9 percent), and 0.08 percent and 0.04 
percent respectively. Education posted 19 forms (28 percent) with 60 occurrences (10.3 percent) representing 0.07 percent of its corpus. In terms of was the most frequent (24 at $298 \mathrm{pmw}$ ) and one-half its occurrence was in Students Essays, where the rate was 600 pmw (the highest for any PNP-construction). Exams and Class Lessons posted 243 and 173 pmw respectively. So why was in terms of most frequent in Students Essays? Could the writers' proficiency level explain the trend? Despite occurring only once each in lieu of, with respect to, by virtue of, and in favour of are of interest because they occurred nowhere else in Education. Students Essays and Exams are samples of students writing; however, whereas Exams contains both university students and secondary school pupils writing, Students Essays reflect university students' scripts only. The PNP-constructions were infrequent in Exams-where the only instance of in contrast with was seen-in comparison with Students Essays, but they both have four forms in common, including with regard to. Though posting the least frequency of PNPconstructions, Class Lessons had the highest incidence of in form of-occurrence in ICE-Nigeria, hosting 57 percent of its 7 occurrences. Whereas its overall frequency was $6.9 \mathrm{pmw}$, the rate was $99 \mathrm{pmw}$ in Class Lessons. This indicates a generous use of analogy, comparison and exemplification in lesson delivery as its collocating nominal complements attest: in form of erm chart, in form of a policy, and in form of a map.

\subsubsection{Science \& Technology}

The PNP-constructions were generally of low frequency in Science \& Technology. There occurred 9 forms (16 percent) that reflected 39 times (6.7 percent) representing 0.05 percent of its corpus and averaging 486 pmw. Only Academic Natural Sciences' occurrence rate of 699 pmw exceeded the mean for ICE-Nigeria; the rates were 550, 498 and 200 pmw respectively for Academic Technical, Popular Technical and Popular Natural Sciences. The forms were almost two times more frequent in Academic Writing (624 pmw) than in Popular Writing (349 pmw). Between strictly science and strictly technology texts however, the latter's rate (523 pmw) was slightly higher than the former's (449 pmw). Only in Academic Technical was the proportion of corpus size that is PNP-construction the same as ICE-Nigeria's 0.06. While it was 0.02 in Popular Natural Sciences, it was 0.05 and 0.07 in Popular Technical and Academic Natural Sciences respectively. In terms of and in addition to figured 225 and 100 times pmw respectively while the single instance of in excess of, in line with, and in conjunction with was barely 13 pmw.

\subsubsection{Mass Media}

Mass Media produced 29 PNP-constructions (51 percent) with 90 occurrences (15.4 percent) representing 0.04 percent of its corpus. The rate of occurrence was $442 \mathrm{pmw}$, which was comparatively low. Two-third of its constituent text types however posted rates in excess of 442. These are Press Reportage (773 pmw), Broadcast Discussions (623 pmw), Broadcast Interview (540 pmw) and Edito- 
rials (450 pmw). Broadcast Talks and Broadcast News posted the lowest frequency of 199 and 147 respectively. In terms of was again the most frequent PNP-construction (119 pmw), and was most frequent in Broadcast Interviews (442 pmw) and Broadcast Discussions (248 pmw). In line with (43 pmw), on behalf of $(30 \mathrm{pmw})$ and in addition to $(25 \mathrm{pmw})$ had low frequency of occurrence (In line with however recorded $175 \mathrm{pmw}$ in Press Reportage). Mass Media had 16 PNP-constructions with no representation elsewhere in the larger corpus. These include in return for, in adherence to, in preparation for, in followership with, and in tune with. The PNP-constructions were almost two times more frequent in Print Media than in Electronic Media. Whereas there were 21 forms (37 percent) with 40 occurrences ( 7 percent) at $666 \mathrm{pmw}$ in the former, the figures were respectively 18 ( 32 percent), 50 (9 percent) and 352 in the latter. The proportion of the corpus was 0.07 percent and 0.04 respectively. Between Press Reportage and Editorials (both Print Media) a ratio of 3:2 was calculated in favour of Press Reportage. The disparity between Broadcast Discussions and Broadcast News was 75 percent, which is ratio 4:1. A wider gap exists between Press Reportage and Broadcast News-the only two text types in ICE-Nigeria specifically containing samples of news-as a ratio of 11:2 (773 pmw v 147 pmw) was found in favour of Press Reportage. The PNP-constructions were thus over five times less frequent in Broadcast News than in Press Reportage. Despite there being no significant difference in their corpus sizes, the number of forms $(17 \mathrm{v}$ 4) with their occurrences $(31 \vee 6)$ was disproportionately skewed in favour of Press Reportage. Since this cannot be explained away in terms of individual news writer's style, the genres themselves, medium, and target audience's literacy level must have had significant influence here.

\subsubsection{Imaginative Writing}

Novels were the only form of creative writing in ICE-Nigeria and this makes Imaginative Writing a one-text-type domain. There were 7 PNP-constructions (12.3 percent) with 17 occurrences ( 3 percent) representing 0.04 percent of the corpus, which translates to a rate of $425 \mathrm{pmw}$. In front of and in spite of were the most frequent forms and were approximately six- and four-times more concentrated in Imaginative Writing than in the entire gamut of ICE-Nigeria. Their 6 and 5 occurrences here-which respectively represent a significant 25 percent and 14 percent of the total-translate to rates of 150 and 125 pmw respectively.

\subsubsection{General Interest Texts}

General Interest Texts is a mixed pot of eight text types grouped together for want of a better classificatory criterion. The constituent text types (Unscripted Speeches, Non-Broadcast Talks, Social Letters, Commentaries, Skills and Hobbies, Phone Calls, Conversations, and Demonstrations) evidently have no underlying relationship except that they contain samples of natural language. So, in terms of genre classification they are quite distinct, although it is not uncommon 
to find identical subject matter straddle files in two separate text types. One example is Elections in Conversations (con_53) and Unscripted Speeches (unsp_43). Another is Independence Celebration in Commentaries (e.g. com_32) and Unscripted Speeches (unsp_32). These instantiations however provide the basis for some meaningful comparison across text types. These remarks having been made, the distribution of the PNP-constructions in GIT can now be addressed.

With its 842 pmw-occurrence Unscripted Speeches had the highest rate of PNP-construction occurrence. The 52 occurrences (8.9 percent) of its 19 forms (30 percent) represent 0.08 percent of its own corpus. In contrast, Demonstrations was the least PNP-construction-bearing text type. Its single-form occurrence (in front of) represents 0.01 percent of its own corpus and translates to a frequency of 49 pmw. Following from the rear with 174 pmw was Conversations, whose 33 occurrences ( 5.5 percent) represent only 0.02 percent of its corpus size. Skills and Hobbies and Phone Calls posted 499 pmw and 450 pmw as rates respectively. The percentage of forms was 10 and 6 and occurrences 10 and 9 respectively, but the proportion of corpus was the same (0.05). Social Letters and Commentaries had 597 and 564 occurrences pmw respectively. Though the number (6/11) and frequency (18/23) of forms differ significantly, the proportion of corpus was the same for both (0.06 percent). Non-Broadcast Talks had the second highest frequency of PNP-construction occurrence (645 pmw), generated by 8 forms (13 percent) with 14 occurrences (2.3) representing 0.06 percent of the corpus.

In general, CPs of the PNP-construction were lowest in GIT (402 pmw) despite posting 31 forms (54 percent) with 159 occurrences (28 percent). These numbers - superseded only by those of Governance \& Law-were accounted for by the sheer number of text types grouped under it, which resulted in a relatively large corpus size, with attendant implications for low frequency and low proportion (0.04 percent). General Interest Texts had the fourth largest concentration of in terms of (139 pmw) after Humanities (175 pmw), Science \& Technology (225 pmw), and Education (298 pmw). The form was least frequent in Imaginative Writing (25 pmw), Governance \& Law (49 pmw), and Business (98 pmw). In terms of s rate of occurrence was over two folds higher in Unscripted Speeches (308 pmw) and Commentaries (245 pmw). It was 89 pmw in Conversations. With one occurrence Social Letters recorded the lowest rate of $33.2 \mathrm{pmw}$. Another PNP-construction of note is in touch with. Ninety-five percent (18) of its occurrence was in GIT and 61 percent (11) of this featured in Social Letters at 364 pmw. Other relatively high frequency PNP-constructions are in front of (11 or 59 percent), on behalf of (10 or 31 percent) and in spite of ( 9 or 25 percent). Unscripted Speeches figured 7 occurrences of on behalf of at a frequency of 350 pmw. Fifty percent of the PNP-forms occurred once only and this includes in search of (Skills and Hobbies), in face of (Commentaries), and in pursuit of and in association with (Unscripted Speeches). Other low-frequency forms are in place of, in honour of and with support of. Finally, one of the two occurrences of 
in respect to and on top of and two of in charge of in ICE-Nigeria were in GIT.

\subsubsection{Informative Texts and Imaginative Texts}

The 32 text types in ICE-Nigeria were re-classified into two using imaginative and informative criteria. This means that 31 (97 percent) were informative while 1 (3 percent) was imaginative. Since facts on Imaginative Writing and its single text type (Novels) are already known, there remains to be added those on Informative Texts. Informative Texts' word count is 970,051, the forms are 63 (100 percent) and their total occurrence is 568 (97 percent). This represents 0.06 percent of the corpus and translates to a frequency pmw of 586, which makes CPs of the PNP-construction one-and-a-half times more frequent in Informative Texts than in Imaginative Writing. A few remarks concerning some domains and text types are necessary at this point. The PNP-constructions were two times more frequent in Academic Writing (811 pmw) than in Popular Writing (374 pmw), as the number and frequency of forms-notably in terms of (22 v 10), in addition to $(9 \mathrm{v} 3)$, in spite of $(6 \mathrm{v} 3)$, and in relation to $(5 \mathrm{v} 1)$-attest. Though Business letters and Social Letters are both epistolary texts, there was a ratio of 3:2 in favour of the former. Again, whereas in touch of was more recurring in Social Letters and on behalf of more frequent in Business Letters, in lieu of, with reference to, in favour of, and in accordance with figured only in Business Letters possibly because of the high degree of formality associated with the genre. Similarly, the relative formality associated with Broadcast Talks could explain its higher rate of PNP-construction-occurrence (645 pmw) in comparison with Non-Broadcast Talks (199 pmw). These show that the number and frequency of PNP-constructions in text domains and text types differ considerably according to a combination of factors. This fact cannot be ignored.

\subsection{Semantic Patterns}

Following Klègr (1997), the 63 PNP-constructions with their 585 occurrences in ICE Nigeria were categorised into twenty-five minor and seven major semantic groups. Respect was the most frequent major semantic category, indicated by 49 percent (289) of the forms. It was distantly followed by process (106 or 18 percent), delimitation (84 or 14 percent), contingency (76 or 13 percent), place (30 or 5 percent) and time (1 or 0.2 percent). No evidence of degree was found. Of the minor semantic categories respect/disregard was the highest occurring, followed by agreement. Subject matter, benefit, condition, detriment, guidance, and identification were not indicated. Table 9 exposes these and more details. Each major semantic category is hereafter taken in turns, complemented with extracts from the text types.

\subsubsection{Respect}

Fifteen PNP-constructions bearing the nouns respect (3), reference (2), support (2), regard (1), favour (1), view (1), terms (1), relation (1), light (1), association (1) and connection (1) expressed respect 289 times in all the domains and text 
Table 9. Semantic manifestations of the PNP-constructions in ICE-Nigeria.

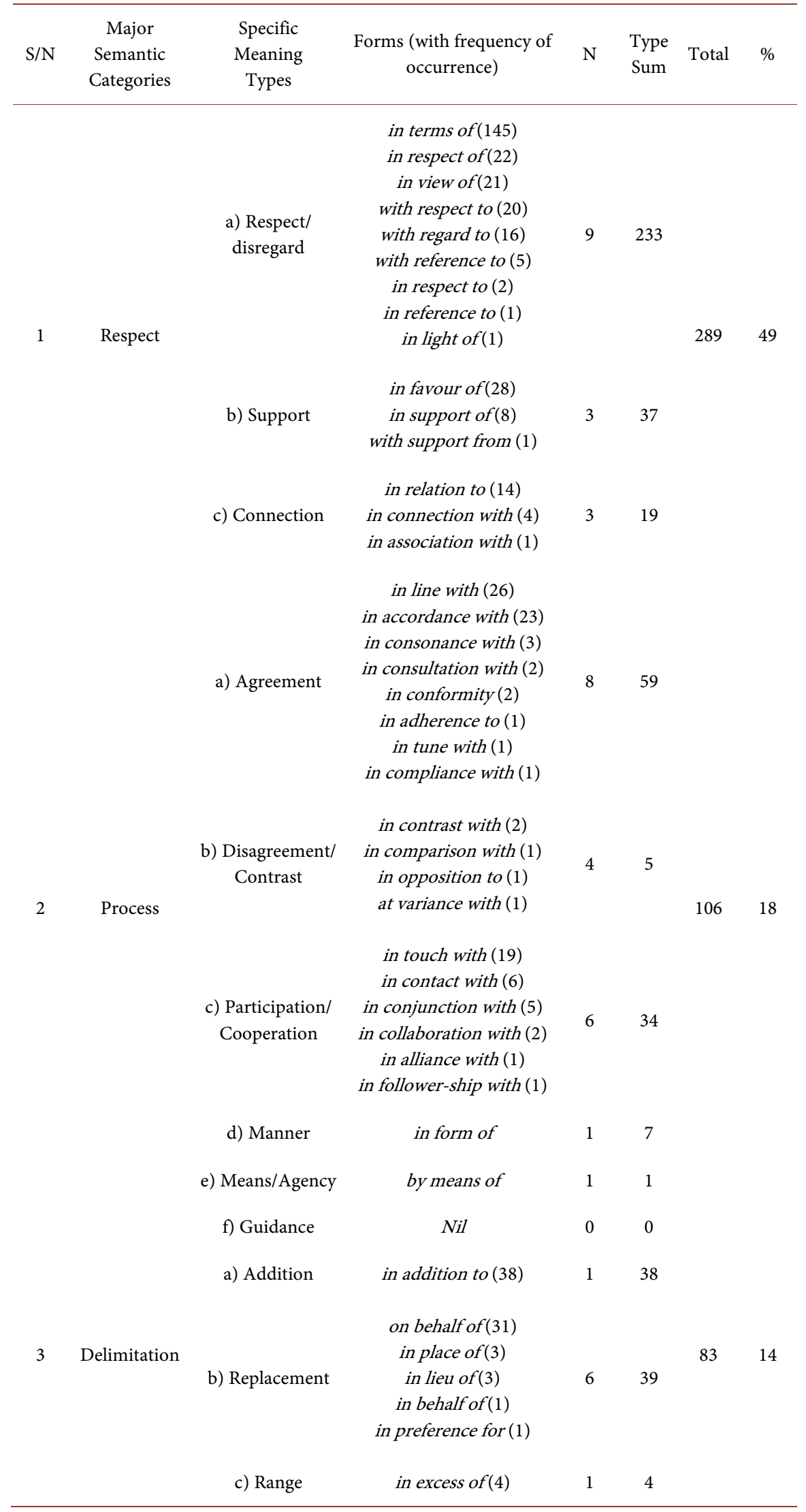




\section{Continued}

4 Contingency

a) Purpose/goal

$\begin{array}{lccc}\text { d) Possession } & \text { in absence of }(1) & 1 & 1 \\ \begin{array}{c}\text { e) Originator/ } \\ \text { Initiator }\end{array} & \text { by order of } & 1 & 1 \\ \text { f) Detriment } & \text { Nil } & 0 & 0 \\ \text { g) Subject Matter } & \text { Nil } & 0 & 0\end{array}$

a) Concession

in spite of $(36)$

in face of $(1) \quad 3 \quad 38$

without prejudice to (1)

in response to (8)

in honour of $(7)$

in preparation for (1)

in pursuance of $(1)$

in pursuit of $(1)$

in memory of (1)

$9 \quad 22$

in search of $(1)$

with view of $(1)$

in order for (1)

by virtue of $(12)$

b) Cause-reason

in recognition of $(3)$

in return for (1)

d) Condition

Nil

$0 \quad 0$

a) Location

in front of (25)

on top of (2)

$2 \quad 27$

$5 \quad$ Place

b) Position/

in charge of(3)

13

Responsibility

6 Time

Time

in times of $(1)$

1

$7 \quad$ Degree

Nil

Nil

Total

types. General Interest Texts emerged the domain with the highest number of respect meanings (79 or 27.6 percent), followed by Governance \& Law (61 or 21 percent) and Mass Media (42 or 14.7 percent). Imaginative Writing and Business posted the lowest percentages of 0.7 and 7 respectively. Education (31 or 10.8 percent), Humanities (28 or 9.8 percent), and Science \& Technology (23 or 8 percent) ranked fourth, fifth and sixth respectively. Respect meaning was generally poorly indicated in academic and popular writing, particularly Popular Social Sciences, where only one instance was recorded. Unscripted Speeches ranked highest in respect meaning manifestation (32) while Demonstrations and Skills and Hobbies had none. Conversations (16), Broadcast Discussions (14), and Commentaries (10), Cross-examinations (10), Academic Technical (9), Exams (8) and Novels (2) featured respect meaning as the enclosed figures show. The 
three strains of respect meaning are examined next.

\section{1) Respect/Regard}

Respect/disregard was the dominant respect meaning with 233 indications representing 81 percent. It was the only meaning found across the 32 text types (excepting Popular Social Science, Demonstrations, and Skills and Hobbies) and it accounted for 40 percent of the semantic manifestations of PNP-constructions in ICE-Nigeria. Thirteen text types were respect/disregard-meaning-only texts and these include Administrative Writing. In terms of, in respect of, in view of, and with respect to were prominent among the 9 indicating forms, illustrated as follows.

(8a) With reference to that yes my Lord you are sure those are their arguing? yes my Lord erm in a situation where parties have erm filed matter for a situation that is erm very primal.

(ICE-Nigeria, leg_07 L245)

(8b) Now in re-in reference to this erm issues of this nature President Richard Nixon had opportunity to tell the parliament that if you dodge away from your responsibilities you certainly will not escape from the consequences.

(ICE-Nigeria, parl_06 L21)

(8c) It is difficult to rationalise dezincification in terms of preferential zinc dissolution out of the brass lattice structure.

(ICE-Nigeria, ess_12 L182)

(8d) In all Xmas is a blessing whether in terms of feeding or whether in terms of meeting partners.

(ICE-Nigeria, ph_02 L400)

(8e) Do you know the exact amount that came into your possession in respect of these properties especially that of ANON?

(ICE-Nigeria, cr_08, L96)

(8f) I was paid how much twenty thousand, the sum of twenty thousand naira in respect to twenty thousand naira, right. Who paid?

(ICE-Nigeria, cr_10 L411)

(8g) In view of the problems being encountered in funding the tertiary institutions using the traditional campus model, there is need to consider an alternative that is more cost effective.

(ICE-Nigeria, AHum_01 L2)

(8h) Following the recent classification of Nigeria by the United States as a country to watch with respect to terror related activities the Nigerian senate has described the classification as unacceptable.

(ICE-Nigeria, bnew_14 L1)

(8i) Maize (...) is the most important cereal in the world after wheat and rice with regard to cultivation areas and total production (...)

(ICE-Nigeria, PNsc_01 L3)

(8j) That distinction remains very interesting, and it is useful, in light of subsequent developments, to revisit his paper. 
(ICE-Nigeria, ess_01 L48)

\section{2) Support}

Support was expressed 37 times and was more generously indicated in Parliamentary Debates, which accounts for 41 percent (15) of its total manifestation, than in the other 16 text types, including Business Letters (4), Legal Presentations (2) and Students Essays (1).

(9a) We humbly acknowledge that your lordship exercise the court's discretion in favour of the defendant and admit him to bail Sir.

(ICE-Nigeria, leg_03 L117)

(9b) Order nine rule two and it says here that a member shall read short extracts from books or papers in support of his argument.

(ICE-Nigeria, parl_04 L320)

(9c) Today, the governing elite in Saudi Arabia is under attack and stiff opposition from religious extremist inside the country with support from fundamentalists outside.

(ICE-Nigeria, AHum_05 L161)

In favour of and in support of are near synonyms as shown below.

(9d) To say that the government is in support of court decisions is to give the impression that it has a choice not to do so.

(ICE-Nigeria, ed_14 L31)

(9e) Some INEC staff who served as electoral officers were said to have been given the bribe to rig the election in favour of the Peoples Democratic Party (PDP).

(ICE-Nigeria, pr_36 L14).

In favour of is also synonymous with in benefit of and in preference in (9f)-(9h) and (9i) respectively.

(9f) A First Bank Draft No (...) dated 11th May 2008 of N 100,000.00 (One hundred thousand naira) in favour of the Bursar, University (...) is attached.

(ICE-Nigeria, bl_69 L27)

(9g) Erm we've seen sixty eight minutes gone and it is three-two in favour of Togo.

(ICE-Nigeria, com_54 L712)

(9h) People voted for erm erm CPC Party, and the election was rigged in favour of $\mathrm{PDP}$.

(ICE-Nigeria, con_53 L42)

(9i) The Hausas (...) preferred to sacrifice their pagan culture in favour of their language.

(ICE-Nigeria, PHum_19 L181)

\section{3) Connection}

In contrast to support where there was a sort of dominance, connection was almost evenly spread among 10 text types, including Press Reportage (3) and (2) Popular Social Sciences (1).

(10a) (...) Stanley (...) pleaded guilty to conspiracy to violate the FCPA in 
connection with a scheme to bribe Nigerian government officials in order to obtain (...) contracts worth US $\$ 6$ billion.

(ICE-Nigeria, pr_31 L35)

(10b) (...) NLC is is going and erm erm TUC of Nigeria they are going with a-a-in a in association with OATUU we are going to embark on voter education.

(ICE-Nigeria, unsp_47 L19)

(10c) Now that we have seen language in relation to the reforms agenda, let us revisit an issue which we have in this country.

(ICE-Nigeria, AHum_09 L67)

\subsubsection{Process}

Process featured in 6 domains-GIT (34), Governance \& Law (25), Mass Media (16), Humanities (10), Education (10), Business (7) and Science \& Technology (2) -and in 23 text types. Unlike agreement and participation/cooperation with 59 and 34 manifestations respectively, means-agency (1), manner (7), and disagreement (11) were low-frequency meanings. All 6 process meanings are examined as follows.

\section{1) Agreement}

Agreement was the process meaning with the widest spread (16 text types). It was the dominant process meaning in Parliamentary Debate (9 of 11) and the only kind in Administrative Writing (9) and Press Reportage (8), with in line with and in accordance with as the main PNP-constructions. Agreement was indicated only once in Exams, Academic Writing Technical, and Commentaries. Here are illustrations.

(11a) The judicial powers vested in accordance with the foregoing provisions of this section (...) (c) shall not except as otherwise provided by this Constitution, extend to any issue or question as to whether any act of omission by any authority or person or as to whether any law or any judicial decision is in conformity with the Fundamental Objectives and Directive Principles of State Policy set out in Chapter II of this Constitution;

(ICE-Nigeria, adm_01 L143,153)

(11b) There are twenty-two dialects of the Urhobo language in consonance with the twenty-two Kingdoms (...)

(ICE-Nigeria, AHum_07 L104)

(11c) I have with me the original act which I have brought earlier in compliance with your earlier ruling.

(ICE-Nigeria, parl_16 L27)

(11d) The legislature (...) and law enforcement organisations must continue to be reoriented in tune with this democratic culture.

(ICE-Nigeria, btal_28 L20)

(11e) Your programme of visit is very much in line with the desire of our university for collaboration and exchange programmes between staff and students of different universities.

(ICE-Nigeria, bl_24 L6) 
(11f) In adherence to this, banks whose year-ends do not coincide with December 31, should inform the CBN of the number of months to be covered by their next audited accounts (...)

(ICE-Nigeria, pr_56 L40, 45)

(11g) Notwithstanding the provisions of subsection (4) of this section, the President, in consultation with the National Defence Council, may deploy members of the armed forces of the Federation on a limited combat duty outside Nigeria $(\ldots)$

(ICE-Nigeria. adm_01 L97)

\section{2) Disagreement/Contrast}

Four low-frequency PNP-constructions expressed disagreement/contrast in 5 texts thus:

(12a) If you put yesterday in comparison with today and the free flow of traffic $(\ldots)$,

(ICE-Nigeria, bint_03 L407)

(12b) Please judge sir completely in opposition to the summons of bail for the applicant dated the twenty first day of May two thousand and twelve.

(ICE-Nigeria, leg_01 L114)

(12c) Those who have come before parliament this morning are saying that the action of the state government is at variance with that law.

(ICE-Nigeria, parl_03 L73)

(12d) There could be cases where what the learner wants is in contrast with what the ESP expert has diagnosed as his or her needs.

(ICE-Nigeria, ex_26 L176)

\section{3) Participation/Cooperation}

Participation/Cooperation featured in 13 text types including Broadcast Discussion, Editorials, and Skills and Hobbies where it was the only process meaning indicated. It was thinly spread, except in Social Letters (11) and Conversations (5) where a kind of dominance was seen in respect of in touch with, and in Phone Calls (4) where it was the only other prepositional meaning outside respect/regard expressed 5 times by in terms of. Here are the extracts. Notice a difference in the meaning of in contact with: the one is physical and the other intellectual.

(13a) During your service to ANON law agency did you ever come in contact with the property or monies of ANON law chamber?

(ICE-Nigeria, cr_6 L181)

(13b) I'm sure that one or two of you must have come in contact with Chinua Achebe Wole Soyinka Buchi Emecheta.

(ICE-Nigeria, unsp_09 L6)

(13c) And in consonance and in followership with what even Mister President is advocating one man one vote for proper and true democracy.

(ICE-Nigeria, bdis_22 L389)

(13d) In the year two thousand and ten the customary court of appeal in col- 
laboration with the national judicial institute organised a one-week training workshop for chairmen and members of all the thirty two customary courts in Rivers state.

(ICE-Nigeria, nbtal_09 L51)

(13e) (...) Mercedes Benz/Weststar, in conjunction with their strategic partners, is ensuring that professional training is given about buses, such as Marcopolo Buses.

(ICE-Nigeria, PTec_30 L42)

(13f) (...) I now have your e-mail address and as such, I can get in touch with you any time I wish.

(ICE-Nigeria, sl_15 L4)

(13g) Saudi State was first formed in alliance with the Wahhabi religious movement (...)

(ICE-Nigeria, AHum_05 L153)

\section{4) Manner}

In form of was the only PNP-construction expressing manner and this was more visible in Class Lessons (4) from where (14) is taken.

(14) There is a compulsory contribution that investors must make to the host community in form of soc-social responsibility (...)

(ICE-Nigeria, les_01 L30)

\section{5) Means-Agency}

Means-agency was expressed only once thus:

(15) This is made possible by the existence of common symbols but it is accomplished by means of a process called role taking (...)

(ICE-Nigeria, ASsc_01 L219)

\subsubsection{Delimitation}

As a major semantic category, delimitation reflected in all 8 domains and in 23 text types. It was highest in GIT (20), followed by Business and Mass Media (15 each), and lowest in Imaginative Writing (1). Education, Science \& Technology, Governance \& Law, and Humanities posted 11, 9, 7 and 4 instances respectively. The text types in which delimitation was expressed include Business Letters (8), Unscripted Speeches (8), Business Transactions (7), and Academic Natural Sciences (6). The five strains of meaning present are examined separately.

\section{1) Addition}

Expressed by the PNP-construction in addition to, addition (38 or 47 percent) was the only strain found in all the domains and text types in which delimitation was indicated. Its primitive meaning "extra" underlines its usage in every instance as the extracts show.

(16a) (...) oils from almond seed and castor seed, in addition to palm oil and groundnut oil may be considered as Nigeria potential asset for biofuel and oleochemical production.

(ICE-Nigeria, ANsc_07 L26)

(16b) So I would like this body this conference to penalize those who have not 
paid. They must pay and in addition to paying they must pay something for not obeying the rules.

(ICE-Nigeria, btr_09 L384)

\section{2) Replacement}

Although replacement slightly surpassed addition in terms of frequency (39 or 48 percent), its sphere of influence was restricted to 5 domains and 16 text types. Five PNP-constructions-on behalf of (31), in place of (3), in lieu of (3), in behalf of (1) and in preference of (1)-expressed this meaning in the number of times indicated in brackets. It was more concentrated in Business Letters (8) and Unscripted Speeches (7), with on behalf of as the main form. The extracts that follow illustrate all the forms except in behalf of, a syntactic variant of on behalf of, shown in (22d) below.

(17a) I write on behalf of Management to acknowledge receipt of your notification of end of sabbatical appointment with the University.

(ICE-Nigeria, bl_63 L10)

(17b) Are they fighting for position or do they speak on behalf of the average farmer on the street?

(ICE-Nigeria, unsp_13 L35)

(17c) Please do you know something that I can eat in place of the food I used to eat?

(ICE-Nigeria, con_14 L264)

(17d) The Vietnamese had, at a time, fallen prey to the French who imposed French language on them but out of national pride, they discarded it in preference for their own-Vietnamese.

(ICE-Nigeria, AHum_01 L181)

(17e) The appointment will terminate by either party hereto giving the other a three-month notice in writing of intention to do so (or by tendering payment of three months' salary in lieu of notice) unless the consent of the Council has otherwise been obtained.

(ICE-Nigeria, bl_55 L39)

\section{3) Range}

The only CP that expressed range as meaning was in excess of and this was in Broadcast Discussion (2), Broadcast Interview (1) and Academic Natural Sciences (1).

(18) From this, the duration of flooding in the study area was determined, and this is the period when rainfall is in excess of evapotranspiration.

(ICE-Nigeria, ANsc_10 L122)

\section{4) Possession}

Again, only one $\mathrm{CP}$ conveyed possession as meaning thus:

(19) So in absence of that we are going to do post item analysis.

(ICE-Nigeria, les_08 L192)

\section{5) Originator/Initiator}

Excerpt (20a) illustrates the only manifestation of originator/initiator. Notice 
its orthographic uniqueness. Notice also that the minor sentence in which by order of occurs is reconstruct-able as in (20b).

(20a) (...) ANY OFFICER OR AGENT INVOLVED IN THIS CONTRAVENTION IS PUNISHABLE BY PERSONAL INCOME TAX ACT 1993 AMENDED. BY ORDER OF LAGOS STATE INTERNAL REVENUE SERVICE.

(ICE-Nigeria, adm_17 L5)

(20b) This notice is given by order of Lagos State Internal Revenue Service.

\subsubsection{Contingency}

Contingency accounted for 13 percent of the total meaning spectrum of CPs in ICE-Nigeria. It figured 16 forms with 76 occurrences in the 8 domains and 26 text types, and was highest in GIT (16 or 21 percent) and lowest in Business (3). Contingency featured in the other domains as follows: Mass Media (13), Governance \& Law (12), Humanities (10), Education (8), Imaginative Writing (8), and Science \& Technology (7), and Business (3). Relative to its corpus size however, it was most frequent in Imaginative Writing (200 pmw). Concession accounted for 50 percent of contingency meaning while purpose-goal and cause-reason represent 29 and 21 percent respectively.

\section{1) Concession}

Three PNP-constructions-in spite of (36 or 95 percent), in face of (1) and without prejudice to (1; See (5) above)-expressed concessive meaning 38 times in all domains (except Business) and 23 text types. Novels had 5 manifestations while Students Essays, Skills and Hobbies, and Unscripted Speeches had 3 each. Concession was very thinly spread among the other text types.

(21a) Adunni's eyes were dried by the sunny reflection from the old man's incredibly shameless act. It was a comic diversion from the tragedy of her son. If only I could be that modest, thought Adunni in spite of the sorrow that held her captive.

(ICE-Nigeria, nov_19 L161)

(21b) The AC said his arrest, in spite of a subsisting court order restraining the police from such an action, is a huge setback for President Umaru Yar' Adua's rule of law mantra.

(ICE-Nigeria, pr_39 L32)

(21c) In face of what they have been able to put in here it might just say that Togo (...) have not been erm totally undeservedly.

(ICE-Nigeria, com_54 L712)

\section{2) Purpose-Goal}

Purpose-goal was present in all domains and was almost evenly distributed among the 13 text types in which it was instantiated. Only in Press Reportage were there 4 occurrences; it featured either twice (e.g. Commentaries) or once only (e.g. Broadcast News) in the rest. Nine PNP-constructions dominated by in response to and in honour of indicated purpose-goal as meaning as shown below.

(22a) In response to customers continued yearning for improved and quality products (...) Nokia last week unveiled a mobile computer, Nokia N97 mini in Lagos. 
(ICE-Nigeria, PTec_33 L2)

(22b) We (..) it is our tradition that the governor receives or holds a dinner in honour of the association.

(ICE-Nigeria, btr_05 L483)

(22c) Many of them travel here and there in search of greener pasture in several multinational companies (...)

(ICE-Nigeria, SkHo_06 L4)

(22d) I hereby humbly write in behalf of Family who would like to institute an annual award in memory of our daughter.

(ICE-Nigeria, bl_69 L19)

(22e) (...) We therefore, in pursuance of these ideals and of the welfare of all persons in the Chapel, on the principle of freedom, equality and justice, do hereby make, enact and give to ourselves this Constitution:

(ICE-Nigeria, adm_11 L13)

(22f) (...) Samson Siasia has expressed frustration at the inability of his boys to play friendly matches which are up to standard in preparation for the Under-20 World Cup (...)

(ICE-Nigeria, pr_51 L4)

(22g) The framework is in pursuit of the development of the endonormative model.

(ICE-Nigeria, unsp_02 L274)

(22h) The third defendant cannot act as the general overseer with view of Ekiti State and I so hold.

(ICE-Nigeria, leg_13 L264)

(22i) In order for Nigeria to benefit maximally from Commonwealth Scholarship and Fellowship Plan programmes, there is need for diversification of the present award scheme (...)

(ICE-Nigeria, ASsc_05 L229)

\section{3) Cause-Reason}

Three PNP-constructions led by by virtue of (12) indicated cause-reason 16 times in all domains (less Science \& Technology) and 13 text types including Press Reportage (3), Legal Presentations (2) and Editorials (1). Cause-reason featured 5 times each in Governance \& Law and Mass Media, and thrice in $\mathrm{Hu}$ manities.

(23a) We host from year to year but not that by virtue of hosting you become president.

(ICE-Nigeria, btr_10 L29)

(23b) When such a society comes into existence, the Holy Quran and the Prophet prescribe for it a code of life called Sharia, and this society is bound to conform to it by virtue of the contract into which it has entered.

(ICE-Nigeria, AHum_08 L179)

(23c) (...) Joachim Löw and his world cup squad were honoured with the highest state award in Berlin in recognition of their performance at the World Cup in South Africa. 
(ICE-Nigeria, bdis_21 L86)

(23d) But Tom, through his lawyer Ikenna Enekweizu, denied offering to surrender in return for the amnesty promised by the President.

(ICE-Nigeria, pr_32 L12)

\subsubsection{Place}

The major semantic category place was indicated 30 times by in front of (25), on top of (2), and in charge of (3) in 6 domains and 11 text types. Location was the dominant place meaning (90 percent), as position/responsibility, expressed by in charge of, accounted for only 10 percent. Place was highest in GIT (14) and lowest in Education (1). Imaginative Writing presented 6.

(24a) She had pictures of herself at Trafalgar Square, in front of shops in Oxford Street $(. .$.

(ICE-Nigeria, nov_04 L47)

(24b) Scattered across the street, in front of what used to be residential buildings only, are displays of a variety of Kampala in different shades and colours.

(ICE-Nigeria, PSsc_14 L21)

(24c) And I discovered that heaven is right on top of Delta. That is why in spite of everything we are doing well.

(ICE-Nigeria, unsp_37 L14)

(24d) Yes, why there is no doctor yeah they are in charge of $\mathrm{f}$-patients where there is no doctor yeah $\mathrm{mhm}$.

(ICE-Nigeria, con_48 L644)

\subsubsection{Time}

Time was expressed only once thus:

(25) Hence most religions, if not all, turn to God (...) in times of need and difficulties.

(ICE-Nigeria, AHum_05 L37)

\subsection{Comparison with BNC}

This section presents and discusses results of the comparison between BNC and ICE-Nigeria with respect to the occurrence and distribution of CPs of the PNP-construction. The analysis relied on aspects of Hoffmann's (2005) findings on the 30 most frequent CPs in BNC, low frequency forms, and in terms of.

\subsubsection{The 30 Most Frequent PNP-Constructions}

Hoffmann (2005: p. 23) lists the 30 most frequent CPs in BNC with their occurrences in descending order of magnitude. To facilitate comparison with ICENigeria I calculated each form's frequency of occurrence per million words. As Table 10 shows, 83 percent (25) of the 30 most frequent PNP-constructions in BNC occurred in ICE-Nigeria while 17 percent did not manifest. The forms present in BNC but absent in ICE-Nigeria are by way of, in contrast to, in need of, in common with, and by reference to. Thirty-six percent (9) of those present were more frequent in ICE-Nigeria than in BNC. This includes in terms of, on 
Table 10. Comparison between BNC and ICE-Nigeria.

\begin{tabular}{|c|c|c|c|c|c|c|}
\hline \multirow{2}{*}{$\mathrm{S} / \mathrm{N}$} & \multirow{2}{*}{ PNP-Constructions } & \multicolumn{2}{|c|}{$\mathrm{BNC}$} & \multicolumn{2}{|c|}{ ICE-Nigeria } & \multirow{2}{*}{ Ratio } \\
\hline & & Occurrence & Freq. (pmw) & Occurrence & Freq. (pmw) & \\
\hline 1 & in terms of & 10,060 & 100.7 & 145 & 144 & $2: 3$ \\
\hline 2 & in front of & 6118 & 61.18 & 25 & 24.7 & $5: 2$ \\
\hline 3 & in relation to & 4668 & 46.68 & 14 & 13.9 & $7: 2$ \\
\hline 4 & in favour of & 3525 & 35.25 & 27 & 26.7 & $3: 2$ \\
\hline 5 & in addition to & 3426 & 34.28 & 38 & 37.6 & $2: 2.2$ \\
\hline 6 & in respect of & 3932 & 29.32 & 22 & 21.7 & $3: 2$ \\
\hline 7 & on behalf of & 2713 & 23.13 & 31 & 30.7 & $2: 3$ \\
\hline 8 & in spite of & 2703 & 27.03 & 36 & 35.6 & $2: 3$ \\
\hline 9 & on top of & 2516 & 25.16 & 2 & 1.98 & $25: 2$ \\
\hline 10 & in accordance with & 2032 & 20.32 & 23 & 22.8 & $1: 1.2$ \\
\hline 11 & in response to & 2004 & 20.04 & 8 & 7.92 & $5: 2$ \\
\hline 12 & with regard to & 1656 & 16.56 & 16 & 15.8 & $1.2: 1$ \\
\hline 13 & in charge of & 1636 & 16.36 & 3 & 2.97 & $33: 2$ \\
\hline 14 & by means of & 1617 & 16.17 & 1 & 0.99 & $17: 2$ \\
\hline 15 & in connection with & 1577 & 15.77 & 4 & 3.96 & $4: 1$ \\
\hline 16 & in view of & 1507 & 15.07 & 21 & 20.7 & $1: 2$ \\
\hline 17 & by way of & 1419 & 14.19 & 0 & 0 & 0 \\
\hline 18 & with respect to & 1330 & 13.3 & 20 & 19.8 & $2: 3$ \\
\hline 19 & in conjunction with & 1267 & 12.67 & 5 & 4.95 & $5: 2$ \\
\hline 20 & in line with & 1241 & 12.41 & 26 & 25.7 & $1: 2$ \\
\hline 21 & in support of & 1083 & 10.83 & 8 & 7.92 & $3: 2$ \\
\hline 22 & in search of & 980 & 9.8 & 1 & 0.99 & $10: 1$ \\
\hline 23 & by virtue of & 953 & 9.53 & 12 & 11.88 & $4: 5$ \\
\hline 24 & in return for & 937 & 9.37 & 1 & 0.99 & $19: 2$ \\
\hline 25 & in contrast to & 877 & 8.77 & 0 & 0 & 0 \\
\hline 26 & in excess of & 835 & 8.35 & 4 & 3.96 & $2: 1$ \\
\hline 27 & in place of & 775 & 7.75 & 3 & 2.99 & $5: 2$ \\
\hline 28 & in need of & 774 & 7.74 & 0 & 0 & 0 \\
\hline 29 & in common with & 773 & 7.73 & 0 & 0 & 0 \\
\hline 30 & by reference to & 660 & 6.6 & 0 & 0 & 0 \\
\hline
\end{tabular}


behalf of, in spite of and with respect to (which posted a ratio of 2:3 in favour of ICE-Nigeria) and in line with and in view of (which maintained a ratio of 1:2). In contrast, 64 percent (16) featured more often in BNC than in ICE-Nigeria. Thus PNP-constructions occurred more frequently in British English than in Nigerian English. Not only were they generally more frequent the differential was a lot wider, as the ratios 33:2, 25:2, 10:1, 19:2, and 17:2 in respect of in charge of, on top of, in search of, in return for, and by means of attest. Only in the case of with regard to (1.2:1) was the differential statistically insignificant $(1.2: 1)$

\subsubsection{Low Frequency Forms}

Hoffmann (2005: p. 142) also provides a list of 132 low-frequency PNP-constructions taken from the written component of BNC. Only 6.1 percent (8) occurred in ICE-Nigeria. They are identified with their numbers in BNC and ICE-Nigeria enclosed in brackets as follows: in respect to (47/2), by order of (85/1), without prejudice to (89/1), in face of $(60 / 1)$, in reference to $(65 / 1)$, in alliance (65/1), in conformity with (65/1), and in compliance with (98/1). Since the written component of BNC comprises 87,284,364 words, their respective frequency per million words amount to $0.54,0.97,1.02,0.69,0.75,0.75,0.75$, and 1.12. Juxtaposing these figures with what there are in Table 4, it is clear that the low-frequency forms were even less infrequent in ICE-Nigeria (the only exceptions being without prejudice to and in compliance with). However, when these figures are viewed from the perspective of the written and spoken components of ICE-Nigeria, it will be seen that they are far more infrequent in BNC than in ICE-Nigeria (See Table 2 and Table 3). Take by order of and without prejudice to, which are the only two in the written component, as examples. Their frequency relative to the 400,796-word corpus is $3 \mathrm{pmw}$, which translates to a ratio of approximately 3:1 in favour of ICE-Nigeria. The rest are in the spoken component and their frequency per million words in the 609,586-word corpus is 2 (except for in respect to with $3 \mathrm{pmw}$ ), which translates to a ratio of 11:2.

\subsubsection{Textual Behaviour}

Comparison between BNC and ICE-Nigeria with regard to the textual behaviour of the PNP-constructions was minimal because data was available only on in terms of and four text types (Class Lessons, Unscripted Speeches, Broadcast Interview and Broadcast Discussions). Nonetheless, I calculated the frequency of in terms of s 7, 19, 9, and 10 occurrences in the respective ICE-Nigeria texts and juxtaposed same with that of BNC (Hoffmann, 2005: p. 126). The differences and percentages of the lower value in each case were subsequently worked out as Table 11 displays.

The occurrence of in terms of in Class Lessons/Lectures was 143 percent higher in BNC than in ICE-Nigeria; it was however 56, 48 and 20 percent more prevalent in ICE-Nigeria than in BNC in respect of Unscripted Speeches, Broadcast Interviews and Broadcast Discussions. This means there was only one 
Table 11. Comparative frequency of in terms of in four text types in BNC and ICE-Nigeria.

\begin{tabular}{cccccc}
\hline S/N & Text Type & $\begin{array}{c}\text { BNC } \\
\text { Freq. (pmw) }\end{array}$ & $\begin{array}{c}\text { ICE-Nigeria } \\
\text { Freq. (pmw) }\end{array}$ & Difference & $\begin{array}{c}\text { Percentage } \\
\text { (of lower value) }\end{array}$ \\
\hline 1 & Class Lessons/Lectures & 411 & 169 & 242 & 143 \\
2 & Unscripted Speeches & 198 & 308 & 110 & 56 \\
3 & Broadcast Interview & 299 & 442 & 143 & 48 \\
4 & Broadcast Discussions & 248 & 206 & 42 & 20
\end{tabular}

text in which its frequency was higher in BNC than in ICE-Nigeria and three in which it was lower. So, although in terms of was the most frequent PNP-construction in both ICE-Nigeria and BNC, there were discrepancies in its distribution in the corpora and these differences are statistically significant. The first striking difference is the respective frequency of 144 and $100.7 \mathrm{pmw}$, which translates to a ratio of 3:2 or a percentage difference of 44 in favour of ICENigeria.

In order to obtain a fuller picture of the pattern of distribution of in terms of in the 32 text types consisting ICE-Nigeria, its frequency was calculated relative to its number of occurrence and the number of words contained in each genre. Space does not permit the listing of all here. However, it must be placed on record that the highest concentration of in terms of was in Students Essays, where a frequency of $600 \mathrm{pmw}$ was seen. Broadcast Interview, Academic Writing Technical, Unscripted Speeches, and Academic Writing Humanities rank between second and fifth with 442, 349, 308, and 300 pmw respectively. The lowest occurrence rates were in Novels (25), Social Letters (33), Legal Presentations (49), Business Talks (50), and Administrative Writing (50). In terms of did not feature in Broadcast News, Demonstrations, Parliamentary Debates, Popular Natural Sciences, Popular Social Sciences, and Skills and Hobbies. While the higher incidence of in terms of-occurrence in the spoken component of ICE-Nigeria-in comparison with its written counterpart-is attributable to known facts about its surfeit in speech, it is difficult to account for the differential between BNC and ICE-Nigeria in like manner. Could it therefore be the case that the hesitation phenomenon associated with this form is more negatively pronounced in Nigerian English (probably due to the L2 situation with its attendant problems) than in British English? Difficulty in immediately recalling the appropriate lexical item or syntactic structure to employ in a given context (which can affect any language user irrespective of whether or not they are a native speaker) tends to be greater where the user's degree of proficiency is lower.

\section{Conclusion}

This final section answers the six research questions that guided the study as concluding remarks (This can only be in brief). That data could be retrieved from ICE-Nigeria and analysed as presented above provides evidence that complex 
prepositions of the PNP-construction also occur in non-native English. Not only did there occur 63 forms with 585 appearances, there were features exhibited that are unique to the variety. Some of these are: 1) the frequency of occurrence was 579 per million words; in terms of, in addition to, in spite of and on behalf of were the most frequent PNP-constructions with respective rates per million words of $144,37.6,35.6$ and 30.7 ; 2) 40.4 percent of the forms posted a single occurrence at a frequency of 0.99 per million words (e.g. in search of); 3 ) the in + noun +of string accounted for 56 percent of the 11 syntactic variants present; and, 4) 32 percent of the forms occurred clause-initially and this includes half the occurrences of in addition to, in spite of, and in view of. With respective occurrence rates of 761 and 461 per million words the PNP-constructions were one-and-a-half times more frequent in written English than in spoken English; however, in favour of, in support of and in contrast with were dominant in the spoken component. Evidence of deviation from the norm came in form of errors, archaism and incomplete realisation of forms. With particular reference to in terms of realised four times as in times of Construction Grammar, which assumes that abstract PNP-constructions are stored in the brain as form-meaning pairings, provided insights to its genesis and indeed that of other errors. If the general processing principles affect first- and second-language speakers in the same manner, as Hoffmann (2011: p. 4) assumes, it could then be the case that the users who committed the errors failed at the point of acquisition to correctly store in their brains the PNP-constructions as form-meaning pairings. There is a strong conviction that if they had been properly stored they would have been correctly retrieved.

Categorising the thirty-two texts in ICE-Nigeria into eight domains allowed for meaningful, cross-sectional comparison. Governance \& Law emerged the domain with the highest frequency of PNP-constructions of 1368 per million words. Business and Humanities followed with 923 and 774 respectively while General Interest Texts and Imaginative Writing posted the least with 402 and 425 respectively. Administrative Writing was the text type with the highest frequency of PNP-construction occurrence of 2151 per million words, followed by Parliamentary Debates and Students Essays with 1686 and 1350 respectively. The PNP-constructions were least frequent in Demonstrations, Broadcast News and Conversations, which recorded 49, 147 and 174 occurrences per million words respectively. Respect was the most prominent of the six semantic categories present. While it accounted for 49 percent of the data, process, delimitation, contingency, place and time respectively represent $18,14,13,5$ and 0.2 percent. Respect/disregard accounted for 81 percent of respect meanings and 40 percent of the total meaning manifestation, and was the only meaning type found in all the domains and text types (excepting Popular Social Sciences, Demonstrations, and Skills and Hobbies). Greatly boosted by in terms of which accounted for 62 percent of its manifestations, respect/regard was the dominant meaning in Unscripted Speeches and the only respect meaning in Administrative Writing. Agree- 
ment followed distantly with 10 percent as the process meaning with the widest text spread; it was dominant in Parliamentary Debates, Administrative Writing and Press Reportage with in line with and in accordance with as its prominent forms. Four meanings in the proportion of 6 percent are replacement, addition, concession and support, and on behalf of, in addition to, in spite of and in favour of respectively indicated 80, 100, 95 and 76 percent of them. Possession, means/agency and originator/initiator were the low-frequency meanings. The PNP-constructions were semantically monostratal in the sense that, with the probable exception of in favour of, each expressed only one strain of meaning. For example, only the place meaning of on top of was seen while in line with did not display its place meaning.

Similarities and differences exist between Nigerian English and British English with respect to complex prepositions of the PNP-construction. To begin with the 63 forms identified in ICE-Nigeria are all present in BNC and in terms of is the most frequent PNP-construction in both corpora. However, while only 6 percent of BNC's 132 low frequency forms occurred in ICE-Nigeria, 17 percent of the 30 most frequent PNP-constructions in BNC did not manifest in ICE-Nigeria. Of the number present 64 percent was more frequent in BNC than in ICE-Nigeria and the differential was as wide as ratio $33: 2$ in some respects. In contrast, the margin was narrower and was in the range of ratio $3: 2$ in the 36 percent of cases where ICE-Nigeria posted a higher frequency of occurrence. In terms of was 44 percent more frequent in ICE-Nigeria than in BNC. With particular reference to the text types Unscripted Speeches, Broadcast Interviews and Broadcast Discussions, it was respectively 56,48 and 20 percent more prevalent in ICE-Nigeria than in BNC. Only in Class Lessons/Lectures was in terms of-occurrence higher in BNC than in ICE-Nigeria and the percentage difference was 143. Complex prepositions of the PNP-construction are thus far more frequent in native English than in non-native English.

\section{Conflicts of Interest}

The authors declare no conflicts of interest regarding the publication of this paper.

\section{References}

Cappele, B. (2001). Is Out of a Preposition? Journal of English Linguistics, 29, 315-325. https://doi.org/10.1177/00754240122005468

Carter, R., \& McCarthy, M. (2006). Cambridge Grammar of English. A Comprehensive Guide. Cambridge: Cambridge University Press.

Croft, W., \& Cruise, A. D. (2004). Cognitive Linguistics. Cambridge: Cambridge University Press. https://doi.org/10.1017/CBO9780511803864

Goldberg, A. E. (1995). A Construction Grammar Approach to Argument Structure. Chicago, IL: The University of Chicago Press.

Goldberg, A. E. (2003). Constructions: A New Theoretical Approach to Language. Trends in Cognitive Sciences, 7, 219-224. https://doi.org/10.1016/S1364-6613(03)00080-9 
Goldberg, A. E., \& Suttle, L. (2010). Construction Grammar. Wires Cognitive Science, 1, 468-477. https://doi.org/10.1002/wcs.22

Greenbaum, S. (1996). The Oxford English Grammar. Oxford: Oxford University Press.

Halliday, M. A. K., \& Matthiessen, C. M. (2004). An Introduction to Functional Grammar. London: Arnold.

Hirao, H. (2016). Down Below as a Complex Preposition. English Linguistics Research, 5, 1-6. https://doi.org/10.5430/elr.v5n4p1

Hoffmann, S. (2005). Grammaticalization and English Complex Prepositions: A Corpus-Based Study. London: Routledge.

Hoffmann, T. (2011). Preposition Placement in English: A Usage-Based Approach. Cambridge: Cambridge University Press.

Hoffmann, T., \& Trousade, G. (2013). Construction Grammar: Introduction. In T. Hoffmann, \& G. Trousade (Eds.), The Oxford Handbook of Construction Grammar (pp. 1-12). Oxford: Oxford University Press. https://doi.org/10.1093/oxfordhb/9780195396683.001.0001

ICE-Nigeria. http://sourceforge.net/projects/ice-nigeria

Inoue, A. (2019). English Phraseological Research on Until by/before Working as Complex Prepositions. International Journal of English Linguistics, 9, 1. https://doi.org/10.5539/ijel.v9n1p1

International Corpus of English-Nigeria (2015). http://sourceforge.net/projects/ice-nigeria

Kay, P., \& Fillmore, C. P. (1999). Grammatical Constructions and Linguistic Generalization: The What's X Doing Y? Construction. Language, 75, 1-33. https://www.jstor.org/stable/417472 https://doi.org/10.2307/417472

Klègr, A. (1997). English Complex Prepositions of the Prepositional Phrase Type. Prague Studies in English, 20, 51-78.

McGranahan, W. J. (1971). V in Phrasal and Complex Prepositions in Scientific Russian. The Slavic and East European Journal, 15, 332-338. https://doi.org/10.2307/306828 https://www.jstor.org/stable/306828

Oxford University Press OED (1971) The Compact Edition of the Oxford English Dictionary. Oxford.

Quirk, R., Greeenbaum, S., Leech, G., \& Svartvik, J. (1985). A Comprehensive Grammar of the English Language. London: Longman.

Salihbašić, A. (2018). Complex Prepositions in EU Documentation and Their Croatian Equivalents. Thesis, Tuzla: University of Tuzla.

Strang, B. M. H. (1969). Modern English Structure. London: Edward Arnold.

Tyler, A., \& Evans, V. (2003). The Semantics of English Prepositions. Spatial Scenes, Embodied Meaning and Cognition. Cambridge: Cambridge University Press.

http://www.cambridge/org/9780521814300

https://doi.org/10.1017/CBO9780511486517 